\title{
SWITCHING BETWEEN SIMPLE ADDITION AND \\ MULTIPLICATION: ASYMMETRICAL SWITCH COSTS DUE TO PROBLEM DIFFICULTY
}

\author{
by \\ Evan T. Curtis
}

A thesis submitted to the Faculty of Graduate and Postdoctoral Affairs in partial fulfillment of the requirements for the degree of

Master of Cognitive Science

in

The Institute of Cognitive Science

Carleton University

Ottawa, Ontario

(C)2012

Evan T. Curtis 
Library and Archives

Canada

Published Heritage

Branch

395 Wellington Street

Ottawa ON K1A ON4

Canada
Bibliothèque et

Archives Canada

Direction du

Patrimoine de l'édition

395 , rue Wellington

Ottawa ON K1A ON4

Canada
Your file Votre référence

ISBN: 978-0-494-91494-6

Our file Notre référence

ISBN: $978-0-494-91494-6$
NOTICE:

The author has granted a nonexclusive license allowing Library and Archives Canada to reproduce, publish, archive, preserve, conserve, communicate to the public by telecommunication or on the Internet, loan, distrbute and sell theses worldwide, for commercial or noncommercial purposes, in microform, paper, electronic and/or any other formats.

The author retains copyright ownership and moral rights in this thesis. Neither the thesis nor substantial extracts from it may be printed or otherwise reproduced without the author's permission.
AVIS:

L'auteur a accordé une licence non exclusive permettant à la Bibliothèque et Archives Canada de reproduire, publier, archiver, sauvegarder, conserver, transmettre au public par télécommunication ou par l'Internet, prêter, distribuer et vendre des thèses partout dans le monde, à des fins commerciales ou autres, sur support microforme, papier, électronique et/ou autres formats.

L'auteur conserve la propriété du droit d'auteur et des droits moraux qui protege cette thèse. $\mathrm{Ni}$ la thèse ni des extraits substantiels de celle-ci ne doivent être imprimés ou autrement reproduits sans son autorisation.
In compliance with the Canadian Privacy Act some supporting forms may have been removed from this thesis.

While these forms may be included in the document page count, their removal does not represent any loss of content from the thesis.
Conformément à la loi canadienne sur la protection de la vie privée, quelques formulaires secondaires ont été enlevés de cette thèse.

Bien que ces formulaires aient inclus dans la pagination, il n'y aura aucun contenu manquant. 


\begin{abstract}
Mental arithmetic is an important ability for a variety of situations. Furthermore, reallife arithmetic situations require switching between operations. Participants $(N=64)$ solved single-digit addition and multiplication problems in mixed blocks in alternating runs of two (e.g., addition, addition, multiplication, multiplication). Participants solved addition problems faster than multiplication problems, and solved small problems faster than large problems. Participants also responded more slowly when operation switched. Operation switch costs were higher following large, difficult multiplication problems. Asymmetrical switch costs are attributed to three characteristics of large multiplication problems. First, large multiplication problems have low memory strength and require a longer period of activation to retrieve. Second, large multiplication problems are often solved using less automatic procedures. Finally, a large number of errors are made on large multiplication problems and participants demonstrate post-error slowing effects. Implications for models of mental arithmetic are discussed in the context of task switching research.
\end{abstract}




\section{Acknowledgements}

I would like to thank Jo-Anne LeFevre for providing me with guidance and support, as well as the freedom to pursue the research questions I am interested in. I hope for the opportunity to continue collaborating in the future.

Thank you to all of the math cognition lab members, past and present, for intriguing conversation and mutual support: Geoff Barnum, Lindsay Berrigan, Angelle Bourassa, Corrie Bouskill, Ozlem Cankaya, Kristina Dunbar, Ineke Imbo, Mamy Kalamba, Elizabeth Morran, Aala Ridha, Nicole Robert, Michael Schildknecht, Carla Sowinsky, Edina Torlakovic, Dean Verger, Emma Wells, and Claire Xu.

Thank you to my friends and family for seeing me through the rough patches the life seems to bring.

A special thank you to Jim Lawton for always making sure I have my head on straight. 


\section{Table of Contents}

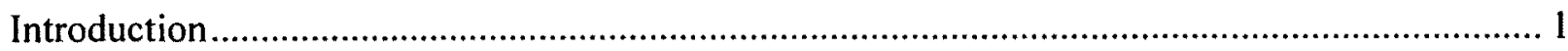

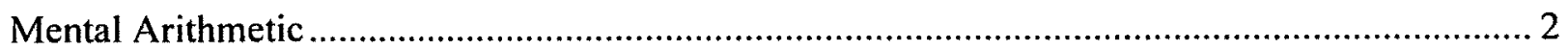

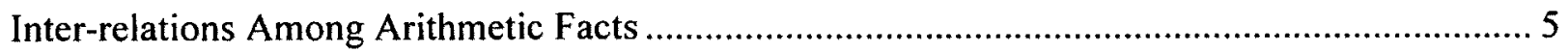

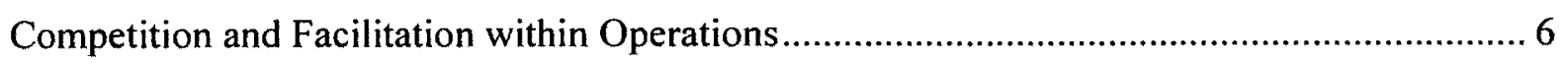

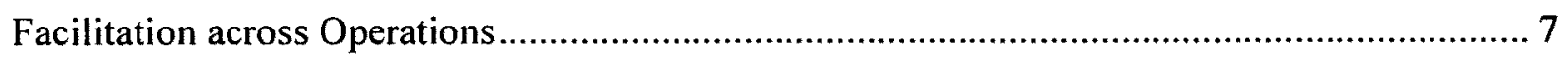

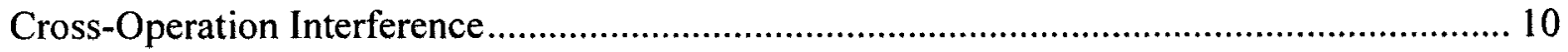

Task Switching and Problem Difficulty ................................................................. 14

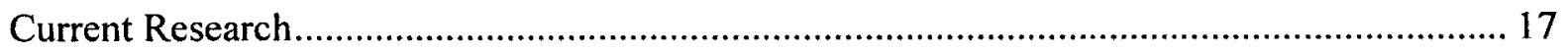

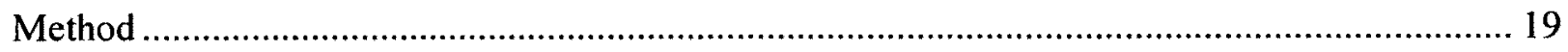

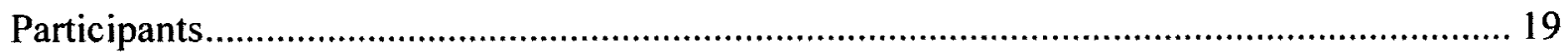

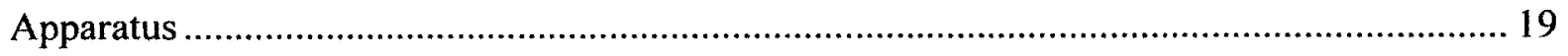

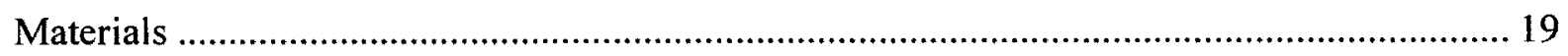

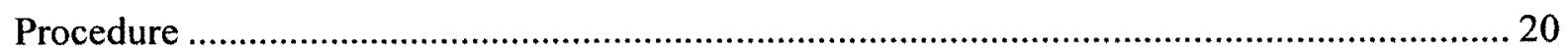

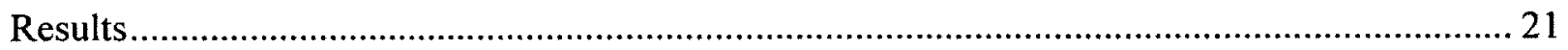

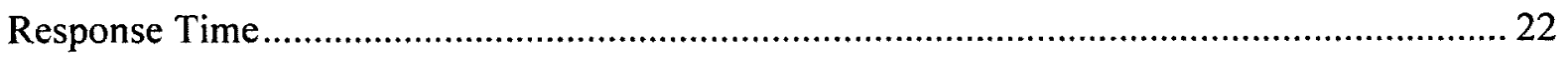

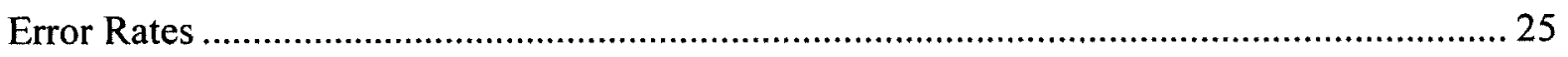

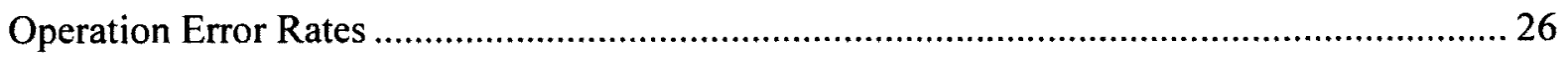

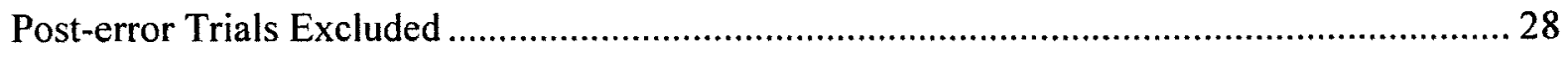

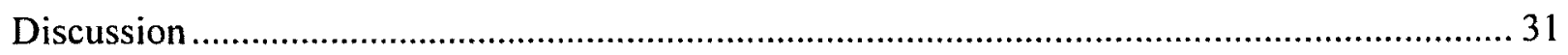

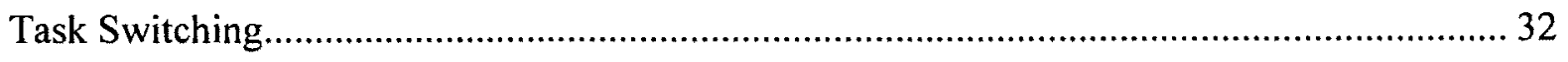

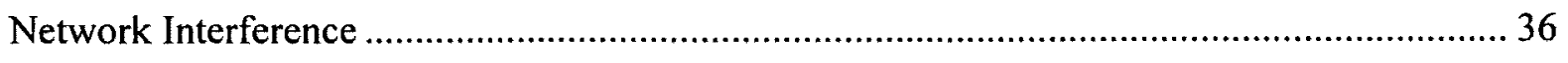

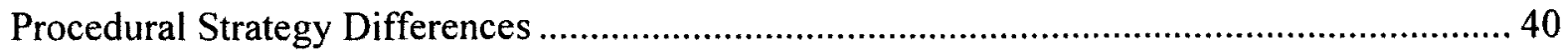




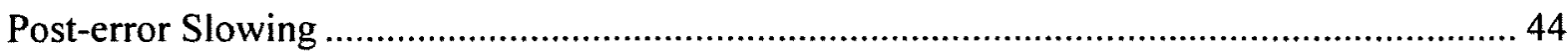

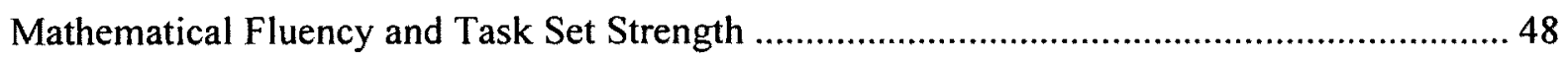

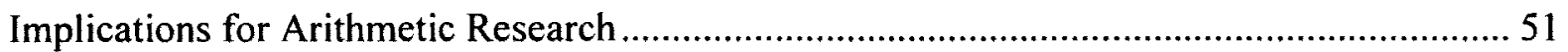

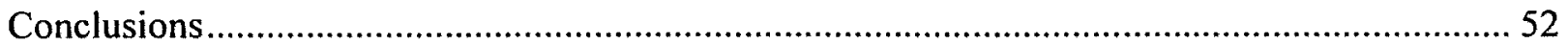

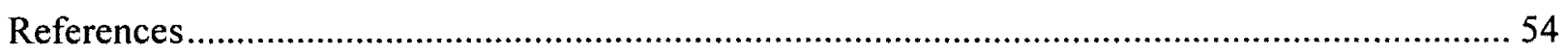




\section{List of Tables}

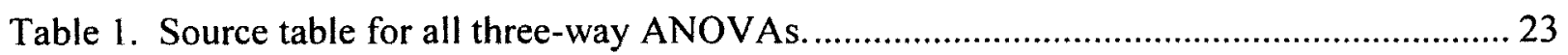

Table 2. Median response times, mean total error rates, and mean operation error rates

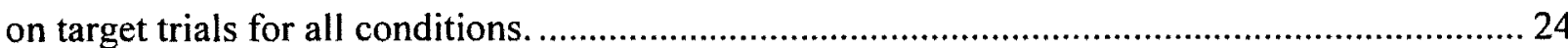




\section{List of Figures}

Figure 1. Response time as a function of sequence, operation, and problem size................... 25

Figure 2. Response time as a function of sequence and operation. .......................................26

Figure 3. Response time as a function of sequence, operation, and problem size, post-

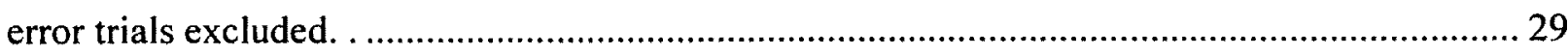

Figure 4. Response time as a function of sequence and operation, post-error trials

excluded. 


\section{List of Appendices}

Appendix A. The full set of problem sequences presented to participants. ...........i 


\section{Introduction}

Simple mental arithmetic (e.g., computing the product of 4 and 6 ) is an important skill that is required in many situations such as calculating taxes, following a recipe, or calculating the time required to travel from one destination to another. As such, understanding the cognitive processes and mechanisms required to perform mental arithmetic quickly and accurately is an important goal (Geary, 2000).

Furthermore, researchers (e.g., Mulhern \& Wylie, 2004) have tracked a consistent decline in the arithmetic ability of adults over the past few decades. This decline increases the importance of understanding mental arithmetic. Most research on mental arithmetic has been focused on solvers' performance of a single operation (addition, subtraction, multiplication, or division). However, many real arithmetic tasks require different operations to be performed in rapid succession (e.g., multiply your total restaurant bill by .15 and add that amount to your total to calculate a tip). Additionally, more complex arithmetic often requires multiple operations (e.g., long division involves a series of multiplications and subtractions). Previous research has demonstrated that performance can often decline when different operations are performed in the context of the same task (e.g., Baddeley, Chincotta, \& Adlam, 2001; Campbell \& Arbuthnott, 2010; Miller \& Paredes, 1990). Thus, the goal of the present research is to examine the performance of mental arithmetic when switching between operations is required, since switching is the norm in real-life situations.

Understanding the interaction between different arithmetic operations will help to inform current models of mental arithmetic not only by generalizing the models to cover all possible arithmetic operations, but also to account for the interdependence 
among those operations. The current work outlines basic models of mental arithmetic, subsequently reviewing the small body of work that has considered operation interactions. Following this review, interference between operations will be considered from the perspective of more general literature on task switching, leading into the current experiment.

\section{Mental Arithmetic}

Consider a standard single-digit arithmetic problem, such as " $4 \times 6$ ". Typically the solution, "24", will be retrieved directly from memory (Campbell \& Xue, 2001; LeFevre et al., 1996). In this case the operands "4" and "6" as well as the multiplication sign all act as cues for retrieval. In predominant models of mental arithmetic, arithmetic facts are stored in an associative network consisting of various problem nodes (e.g., Butterworth, Zorzi, Girelli, \& Jonckheere, 2001; Campbell, 1995; Campbell \& Oliphant, 1992; Verguts \& Fias, 2005a). A problem node stores information regarding the operands and the appropriate solution. When a problem is presented, activation spreads through the network activating competing nodes that share features with the presented problem. As such, the problem " $4 \times 6$ " will activate the node $\{4,6, x, 24\}$. However, it will also activate nodes such as $\{4,7, x, 28\}$ and $\{3,6, x, 18\}$ because those problems share a common operand with the presented problem.

Although models make different assumptions (e.g., whether commutative problems such as $5 \times 7$ and $7 \times 5$ are stored separately), there are three important commonalities. First, spreading activation throughout the network caused by the presentation of a problem causes interference between related nodes. As a result, 
errors are often the solution to a related problem (e.g., solving " 6 x 8" as " 42 "; Campbell, 1994; Campbell \& Graham, 1985). Second, the models are typically models of a single operation. For example, Verguts and Fias' (2005a) model is explicitly described as a model of multiplication, and Butterworth et al.'s (2001) model is explicitly described as a model of addition. Third, the models are often models of retrieval processes exclusively (although see Siegler, 1988). However, arithmetic problems can be solved without directly retrieving the solution. Thus an adequate model of mental arithmetic must incorporate both retrieval processes and the variety of procedures that can be employed to solve a problem.

There are a number of procedures that can be used to solve mental arithmetic problems. Although the use of these procedures is more common in children (Lemaire \& Siegler, 1995; Siegler, 1988), adults also employ non-retrieval solutions on simple arithmetic problems. LeFevre, Sadesky, and Bisanz (1996) collected self-reports from participants on the procedures they used to solve single-digit addition problems (see LeFevre, Bisanz et al., 1996 for an analogous experiment with single-digit multiplication; see Roussel, Fayol, \& Barrouillet, 2002 for contrary evidence using a verification procedure rather than production). Although retrieval was the most frequent procedure reported by LeFevre and colleagues, adults also reported using a variety of alternative procedures. For addition problems, adults report using counting, often from the largest operand (e.g., solve $3+7$ by counting " $7,8,9,10$ "), as well as transforming the question into a more well-known problem to facilitate solution (e.g., $4+8$ solved as $4+6+2$ ). Multiplication problems were also often solved via transformations, as well as repeated addition (e.g., $5 \times 3$ solved as $5+5+5$ ), number 
series counting ( 6 × 5 solved by counting " $6,12,18,24,30$ "), and the nines rule (for 9 $\mathrm{x} n$, the tens digit is $n-1$ and the two units must sum to 9). The wide range of procedures adults use to solve problems suggests that arithmetic is not strictly a process of memory.

Retrieval is fast and efficient, whereas procedural strategies are more time consuming (Smith-Chant \& LeFevre, 2003). Therefore retrieval should be the preferred solution procedure in a time-pressured experimental setting. Furthermore, arithmetic fact retrieval is highly automatic. Presenting a problem primes identification of the solution, even when the problem is presented for as short a period as $32 \mathrm{~ms}$ (Garcia-Orza, Damas-Lopez, Matas, \& Rodriguez, 2009). Automatic activation of arithmetic facts varies as a function of problem size (Jackson \& Coney, 2005), mathematical ability (Jackson \& Coney, 2007), and rote memory capacity (Holmes \& McGregor, 2007). Thus, although adults often retrieve arithmetic facts directly, they often use different procedures to derive the solution. Adults demonstrate considerable variability in the cognitive processes used to solve arithmetic problems, and this variability is partially reflected in response latencies.

The most important variable in research on mental arithmetic is the problem size effect: the finding that solvers make more errors and respond more slowly on problems with larger operands and answers (e.g., $6 \times 8 ; 5+9 ; 15-7$ ) than on problems with smaller operands and answers (e.g., $6 \times 2 ; 5+3 ; 9-4$; Zbrodoff \& Logan, 2005; Ashcraft \& Guillaume, 2009). The problem-size effect is ubiquitous, but arises from several different sources. Large problems are not as well practiced (Ashcraft \& Christy, 1995; Campbell \& Graham, 1985) and therefore have lower 
baseline activation in memory. There is also more interference and less facilitation from other problems for large problems (Verguts \& Fias, 2005a). As a result, large problems require more time to retrieve. Furthermore, because retrieval often fails on large problems, adults are more likely to rely on procedures, which are slower than direct retrieval (LeFevre et al., 1996; LeFevre, Sadesky, \& Bisanz, 1996; Smith-Chant \& LeFevre, 2003). Low memory strength and more frequent use of procedures on large problems work in conjunction to produce the problem size effect.

In summary, current models of mental arithmetic focus on fact retrieval. However, even adults often rely on non-retrieval procedures to solve arithmetic problems. Furthermore, current models are models of a single arithmetic operation. The next section outlines research examining the relationships between different arithmetic facts both within and across different operations.

\section{Inter-relations Among Arithmetic Facts}

Arithmetic problems share common operands, and presumably the mental representations of arithmetic facts contain overlapping features as a result. Arithmetic facts within the same operation interfere with each other under some conditions but may also be mutually facilitating (Campbell, 1995; Verguts \& Fias, 2005a).

Furthermore, arithmetic facts from different operations can also influence each other. The relations between operations sometimes facilitate performance (e.g., Campbell \& Agnew, 2009; LeFevre \& Morris, 1999) and sometimes interfere with performance (e.g., Campbell \& Arbuthnott, 2010; Miller \& Paredes, 1990). Evidence for competition and facilitation within operations, facilitation between operations, and interference between operations is considered below. 


\section{Competition and Facilitation within Operations}

Verguts and Fias' (2005a) interacting-neighbours model of mental multiplication has both facilitative and competitive components. According to their model, multiplication facts are stored in a structurally similar way to a multiplication table. Neighbours are problems that are represented close together in the mental network (e.g., " $4 \times 5$ " and " $4 \times 6$ " are close because they share an operand). Verguts and Fias hypothesized that obligatory activation of neighbouring problems occurs, and retrieving the solution is easier when a problem has high "neighbourhood consistency". Neighbourhood consistency refers to the degree to which the solutions to neighbouring problems share common digits (e.g., $4 \times 5$ and $4 \times 6$ both have answers in the 20s). Problems that are consistent facilitate each other while problems that are inconsistent interfere with each other. Thus problems with high neighbourhood consistency are retrieved more quickly than problems with low neighbourhood consistency.

Verguts and Fias (2005b) presented participants with multiplication problems in separate blocks, some with tie problems (e.g., $4 \times 4,8 \times 8$ ) included and others without tie problems. Past research has demonstrated that if problems are not included in a block of trials then they are not activated (Campbell, 1987). If the tie problems are not activated then the neighbourhood consistency of some problems changes (e.g., $4 \times 3,8 \times 7)$. The problems with the greatest increase in neighbourhood consistency ( 7 $\times 8,8 \times 7,8 \times 9$, and $9 \times 8$ ) were solved much more quickly in the blocks that excluded tie problems than in the blocks that included tie problems. This result suggests that 
even the presence of other arithmetic problems in a block of trials changes how adults solve arithmetic problems.

Other research has demonstrated that when arithmetic facts are retrieved, those facts compete and interfere with each other for an extended period of time. For example, when a solution is retrieved on one problem, the solution is more likely to be produced as an error on a later trial. This phenomenon is known as positive error priming (Arbuthnott \& Campbell, 1996). When a problem is retrieved, the corresponding problem node is activated. On subsequent trials, the problem node has some residual activation and therefore the solution is more likely to be erroneously retrieved. This pattern nicely demonstrates the high degree of interdependence among arithmetic facts stored in an associative network.

The evidence provided above suggests that arithmetic facts within operations sometimes compete with each other and influence arithmetic performance whereas at other times, they may be mutually facilitative. However, arithmetic facts from different operations are also related and show clear interactions.

\section{Facilitation across Operations}

In some cases an arithmetic operation facilitates performance of another operation. LeFevre and Morris (1999) gave participants separate blocks of multiplication problems and division problems. Participants who solved blocks of division problems first were much faster on the subsequent blocks of multiplication problems, suggesting that solving division problems facilitated the solution of multiplication problems. The source of the facilitation was demonstrated via selfreports of solution procedures. Participants often indicated that they solved large 
division problems by "recasting" them as multiplication problems. For example, "56 $\div 7=$ ?" would be recast as " $7 \times ?=56$ ". When participants solve a division problem by recasting it as a multiplication problem, that multiplication problem is primed in memory.

Similarly, Mauro, LeFevre, and Morris (2003) showed participants multiplication and division problems in both standard notation (e.g., " 4 x 5", "20 4") or recast notation ("20 $\div ?=4$ ", " $5 \mathrm{x} ?=20$ "). Division problems were solved more rapidly in the recast notation, whereas multiplication problems were solved more rapidly in the standard notation. Campbell and Robert (2008) demonstrated that multiplication and factoring (e.g., " $14=$ ? $\mathrm{x}$ ?") are mutually facilitative when they are practiced together in the same block. When each is practiced separately, the other operation actually suffers from item-specific interference instead (e.g., practicing " $7 \mathrm{x}$ 2" alone increases response time on " $14=$ ? x ?"). Campbell, Fuchs-Lacelle, and Phenix (2006) further demonstrated that facilitation only occurs when the division problem is solved using a non-retrieval procedure (but see De Brauwer \& Fias, 2011 for facilitation on small division problems). Together, these results suggest that multiplication and division facts are stored in separate networks with some degree of independence, because retrieval of one does not facilitate retrieval of the other and the two can be separated if such separation is adaptive to the experiment. However, division is often mediated by reference to multiplication, and as a result solving division problems sometimes relies on activating the network of multiplication facts.

Rickard and colleagues (e.g., Rickard, 2005; Rickard, Healy, \& Bourne, 1994) suggest that procedural mediation is the only relationship between multiplication and 
division. In their identical elements model, problems will only facilitate each other if their nodes contain exactly the same elements (e.g., $4 \times 6$ will facilitate $6 \times 4$ because they both share the elements $\{4,6, x, 24\}$, whereas $3+7$ will not facilitate $10-7$ because " $10 "$ is an operand in one and a solution in the other). Thus division problems should only facilitate their corresponding multiplication problems when the mediation strategy is used. However, similar facilitation has been observed between addition and subtraction. Campbell and Agnew (2009) found that addition and subtraction produce facilitation that is both item-specific and bidirectional. Facilitation occurred even when the prime trial and target trial were both solved via direct retrieval. Campbell and Alberts (2010) found that this is the case for even the easiest subtraction problems (small problems and tie problems). The relationship between addition and subtraction seems similar to the relationship between division and multiplication, but possibly with less separation between the two networks, or even some sort of common representation (but see Bajic, Kwak, \& Rickard, 2011 for contrary results). Despite predictions from the identical elements model, addition and subtraction problems seem to activate each other even when problems are solved via direct memory retrieval.

Facilitation between multiplication and division, and addition and subtraction, seems sensible given that they are conceptually related to each other. Division and subtraction can be considered inverse versions of multiplication and addition, and this is often how children are taught these operations (e.g., Nunes, Bryant, Hallett, Bell, \& Evans, 2009; Schneider \& Stern, 2009). However, similar facilitation between other operations seems less plausible. Addition and multiplication problems have been shown to interfere with each other. Consider " $6 \times 7$ " and " $6+7$ ": The operands are 
the same and the only difference between the stimuli is the operation sign. Given the similarity between the stimuli, we might expect both the addition and multiplication networks to be activated, causing potentially severe interference. The brief literature on interference between addition and multiplication is considered below.

\section{Cross-Operation Interference}

Zbrodoff and Logan (1986) gave participants addition and multiplication verification problems in pure and mixed blocks. In the verification task, participants are presented with a problem and a solution and they indicate whether the solution is correct or incorrect. The equations presented could be correct (e.g., $3 \times 4=12$ ), incorrect and unrelated to the other operation (e.g., $3 \times 4=14$ ), or incorrect but associated with the correct response in the other operation (e.g., $3 \times 4=7$ ). Participants were consistently slowest on incorrect associated problems, suggesting that the operands automatically activated both networks. Although the effect was present in pure blocks, it was much larger in mixed blocks, suggesting that the activation is not entirely automatic, but partially related to task demands.

Additionally, there were much larger associative effects for multiplication problems, suggesting that in verification tasks addition interferes more strongly with multiplication than multiplication interferes with addition. In subsequent experiments, participants solved verification problems with intermittent stop signals. Once the participant heard the signal, she attempted to stop solving the problem and avoid responding. In a subsequent recognition test, participants were presented with both previously presented and novel problems. Participants reliably failed to recognize 
problems that included a stop signal, suggesting that arithmetic processes are not entirely ballistic and can be inhibited.

Research also suggests that retrieving an arithmetic fact from one operation also involves inhibiting facts from other operations. Campbell and Thompson (2012; see also Campbell \& Phenix, 2009) examined the interfering effects of practicing multiplication on solving addition problems within the framework of retrieval-induced forgetting. Retrieval-induced forgetting has been observed in paired associate learning (e.g., Anderson, 2003, 2005; Phenix \& Campbell, 2004). In these studies, participants study category-exemplar pairings (e.g., drink-beer; drink-juice) and repeatedly performing cued stem completions on half of the exemplars from half of the categories (e.g., drink-b__ _ In a subsequent test phase participants perform stem completions on the entire list. They reliably perform less accurately on unpracticed exemplars from practiced categories (drink-j___ t than on items from unpracticed categories (meat-b__ [beef]). Given that addition and multiplication problems share many overlapping features, Campbell and colleagues hypothesized that retrieval-induced forgetting might occur in arithmetic performance. Participants repeatedly practiced single-digit multiplication problems (e.g., $4 \times 2$ ), then they solved addition problems with either the same (e.g., $4+2$ ) or different operands (e.g., $3+5$; Campbell \& Thompson, 2012). Participants were much slower on addition problems that corresponded to a practiced multiplication problem, but only for small addition problems with high memory strength (e.g., $3+2$ vs. $8 \times 9$ ). Furthermore, the interference only occurred if the multiplication problems were solved rather than simply studied (i.e., participants viewed $3 \times 2=6$ ). These results suggest that 
participants actively inhibited associated addition problems when they practiced solving the corresponding multiplication problem, especially for addition problems that are have strong associate strength and thus are retrieved automatically from memory. This interplay between operations suggests that operands activate problem nodes that share some features, even if the problem nodes are associated with different operations. It follows that although arithmetic facts from different operations might be stored in distinct networks, those networks are not completely separate in memory. The networks are inter-dependent, and the same stimulus (e.g., $3+4)$ activates nodes in multiple networks.

Miller and Paredes (1990) explored a different potential source of crossoperation interference. They proposed that inhibition of addition facts during multiplication might be an artifact of children's learning histories. Typically adults are faster and less error prone in addition than in multiplication (Campbell \& Xue, 2001). Miller and Paredes found that this pattern occurred when adults performed addition and multiplication in pure blocks, where addition was approximately $250 \mathrm{~ms}$ faster than multiplication. However, Grade 3 children solved multiplication problems faster than addition problems, and Grade 5 children solved addition and multiplication problems at approximately the same speed.

Furthermore, Miller and Paredes found that although adults performed addition problems more quickly than multiplication problems in pure blocks, they solved multiplication problems more quickly than addition problems in mixed blocks. Addition problems were solved much more slowly in mixed blocks than in pure blocks, while multiplication problems were solved at similar speeds. Furthermore, 
although errors were most often operation errors, where the participant gives the correct response in the wrong operation (e.g., 21 for $3+7$ ), operation errors were far more likely to occur on addition problems than on multiplication problems. Thus, addition was more influenced by multiplication than the reverse. Miller and Paredes (1990) suggested that when children first learn multiplication, they must inhibit the addition response associated with the same operands. Because addition problems are well practiced and highly automatic, strong inhibition is required and this inhibition is difficult to overcome subsequently when the addition problem is presented. This claim was corroborated by a longitudinal study (Miller \& Paredes, Experiment 2) that demonstrated a marked decrease in addition performance coinciding with the time children started to learn multiplication. Miller and Paredes suggested that this pattern of inhibition persists into adulthood when both operations have to be performed in succession, causing the abnormally poor performance on addition problems in mixed blocks.

However, more recent work raises doubts about the persistent inhibition hypothesis as an explanation of reduced addition performance during mixed blocks of additon and multiplication. Censabella and Noel (2005) demonstrated results similar to Campbell and Thompson (2012) where participants' performance on multiplication problems presented in pure blocks interfered with subsequent blocks of addition problems, but with children instead of adults. However, Censabella and Noel found that the magnitude of the interference was not correlated with the children's inhibitory abilities, as measured by a standard Stroop task (Stroop, 1935), but interference was weaker for children with higher math fluency. Additionally, Campbell and Arbuthnott 
(2010) proposed an alternative explanation for the inhibitory effect of multiplication on addition that was based on local characteristics of the experimental mixed blocks, drawing on more general research in task switching. Before considering their experiment in detail, it is necessary to briefly review task switching research. Task Switching and Problem Difficulty

Human behaviour can change and adapt in response to shifting demands in the environment. Often humans must switch from one task to another very quickly. However, this adaptation requires effort and negatively influences task performance. Task switching has been developed as a paradigm in order to explore the mechanisms that make flexible behaviour possible (for reviews see Allport \& Wylie, 1999; Kiesel et al., 2010; Logan, 2003; Monsell, 2003).

In a typical task switching experiment, participants perform two tasks that share the same stimuli (e.g., parity and magnitude judgments on numbers) in both pure and mixed blocks. Two robust effects are observed: mixing costs and switch costs. Mixing costs refer to the overall deficit in performance when tasks are mixed compared to when tasks are performed separately. Typically participants are slower and less accurate in mixed blocks compared to pure blocks. Switching costs, in contrast, occur on a trial-to-trial basis and refer to a decrease in performance immediately following a task switch compared to a task repetition. Therefore switch costs are local effects measured within mixed blocks whereas mixing costs are global effects measured across blocks. Both mixing and switch costs have been reliably demonstrated in a variety of tasks, including reading words, naming objects, identifying colours, locating stimuli, categorizing vowels and consonants, judging 
number parity, and judging number magnitude. Mental arithmetic is less commonly the focus of task switching research (but see Baddeley, Chincotta, \& Adlam, 2001; Metcalfe \& Campbell, 2011; Schneider \& Anderson, 2010).

A third reliable finding is that mixing and switch costs are asymmetrical for tasks of unequal difficulty (Allport, Styles, \& Hsieh, 1994; Gilbert \& Shallice, 2002; Yeung \& Monsell, 2003): Specifically, costs are greater on the easier of the two tasks. For example, although it is more difficult to name the colour of an incongruent Stroop stimulus than to read the same stimulus (MacLeod, 1992; Stroop, 1935), switching from naming the colour to reading the word results in a greater increase in response time and chance of an error than switching from word reading to colour naming.

Predominant theories of task switching claim that the two tasks belong to separate mental task sets that need to be activated to facilitate performance (e.g., Jersild, 1927; Rogers \& Monsell, 1995; Spector \& Biederman, 1976). On this view, switch costs are produced because the residual activation from the recently performed task interferes with the new task. Difficult tasks require higher levels of activation (Gilbert \& Shallice, 2002; Yeung \& Monsell, 2003), and easier tasks might also need to be concurrently inhibited (Allport, Styles, \& Hsieh, 1994; Arbuthnott, 2008). As such, performing the more difficult task produces high interference when participants switch to the easier task, and they might also require more time to activate the easier task if it was previously inhibited. In contrast, performing the easier task only produces small amounts of interference when participants switch to the more difficult task. This difference in the balance of activation and inhibition produces asymmetrical interference and thus asymmetrical switch costs. 
Campbell and Arbuthnott (2010) argued that the asymmetry between multiplication and addition reported by Miller and Paredes (1990) is simply an instance of more general switch-cost asymmetry. Recent evidence from event-related potentials suggests that multiplication and addition reflect largely unique cognitive processes (Zhou, 2011). Further, behavioural research has shown that multiplication is slower and more error prone than addition in pure blocks and thus is ostensibly a harder task (Campbell \& Xue, 2001). Thus, the asymmetry observed by Miller and Paredes (1990) may largely reflect differential difficulty of multiplication versus addition.

Campbell and Arbuthnott exploited the robust problem size effect to test this hypothesis. The problem-size effect is very reliable for single-digit arithmetic problems, and therefore serves as a valid measure of task difficulty. Campbell and Arbuthnott (2010) gave participants single-digit addition and multiplication problems in both pure and mixed blocks. Their results largely replicated Miller and Paredes (1990): Performance was generally faster and more accurate in pure blocks than in mixed blocks. In pure blocks addition problems were solved more quickly than multiplication problems. However, in mixed blocks addition and multiplication problems were solved at approximately the same speed. Although the crossover effect observed by Miller and Paredes where addition is performed more slowly than multiplication did not occur, the mixing cost was asymmetric -- $114 \mathrm{~ms}$ for addition versus only $44 \mathrm{~ms}$ for multiplication. Campbell and Arbuthnott also found that the mixing cost asymmetry was greater for small problems than for large problems. As expected, small problems were solved much more quickly and accurately than large 
problems overall. Thus, consistent with the task switching literature more generally, the largest switch costs were found on the easiest problems.

Campbell and Arbuthnott's (2010) analyses of trial-by-trial switch costs reveal additional complexity. They analyzed response time as a function of operation, sequence type (switch vs. repeat), and the size of the preceding problem. The three variables interacted. Switch costs for addition problems were much higher following a large multiplication problem compared to a small multiplication problem whereas the size of the preceding addition problem had little influence on the switch cost for multiplication. In short, addition problems suffered a very large asymmetrical switch cost that was related to problem difficulty, whereas multiplication problems did not.

Campbell and Arbuthnott's (2010) results add interesting constraints and qualifications to Miller and Paredes' (1990) findings. Campbell and Arbuthnott provided strong evidence that the difficulty of arithmetic problems makes a substantial contribution to the magnitude of switch costs. However, their experimental design does not permit a complete examination of potential difficult- and operation-related switch costs. Campbell and Arbuthnott analyzed switch costs based on the size of the target problem (i.e., item $n$ ) and the size of the preceding problem (i.e., item $n-I$ ) in separate analyses. However, they report that cell frequencies were too low to analyze both target and $n-1$ problem size in the same analysis.

\section{Current Research}

The experiment described in this thesis provided a further test of Campbell and Arbuthnott's (2010) argument that the differential latency patterns caused by switching between addition and multiplication are an instance of difficulty-related 
asymmetric switch costs. In the present research, I used a paradigm that was similar to that used by Campbell and Arbuthnott, with several modifications. Participants did not complete any pure blocks of trials, because the local switch costs were of primary interest. Furthermore, Campbell and Arbuthnott presented operation cues that preceded the problem for half their participants. This manipulation was not included in the present research because the effects of pre-cueing were not of interest. The current experiment is much more focused on operation switch costs as a function of problem difficulty. Most importantly, the experiment was designed so that both the target and $n-1$ problem size could simultaneously be tested as potential influences on switch costs in mixed blocks of trials. Participants solved single-digit addition and multiplication problems verbally in alternating runs of repeat trials and switch trials. Following Campbell and Arbuthnott (2010), response times, total error rates, and operation error rates were analyzed. I hypothesized that participants would solve problems more slowly when they were required to switch operations, reflecting a switch cost. Additionally, I hypothesized that the magnitude of the switch cost would be greater when the previous problem was more difficult than the target problem (e.g., a large multiplication problem on trial $n-1$ and a small addition problem on trial $n$ ). These hypotheses are consistent with Campbell and Arbuthnott's results. Additionally, the current hypotheses extend Campbell and Arbuthnott by predicting an interaction between target problem size, $\mathrm{n}-1$ problem size, and operation, where switch costs are highest when the $n-1$ problem is more difficult than the target problem (e.g., large multiplication to small addition, large multiplication to large addition, large addition to small multiplication). This prediction is consistent with the 
assumption that it is difficulty of the problems, rather than the nature of the operations, which is central to the asymetrical switch costs across operations.

\section{Method}

\section{Participants}

Sixty-four participants ( 37 female) volunteered for the experiment through the Carleton University SONA recruitment system. Participants received either course credit or $\$ 10$ for participating. Participant ranged in age from 17 to 27 years $(M=$ 17.7). All participants reported normal or corrected-to-normal vision.

\section{Apparatus}

The experiment was programmed in the EyeLink ExperimentBuilder software, version 1.10.1 (SR Research, Inc.). The software was run on a personal computer (PC) using Windows XP. Stimuli were presented on a 15 -inch monitor. Participants responded into a headset microphone connected to an ASIO voice-key trigger accurate to $+/-1 \mathrm{~ms}$, and participant responses were recorded by the experimenter on a standard computer keyboard.

\section{Materials}

Addition and multiplication problems were constructed using all pairwise combinations of operands from 2 to 9 . Commutative problems (e.g., $2 \times 8$ and $8 \times 2$ ) were considered different problems. Problems were separated into small and large problems, where problems with a product of 25 or less were considered small (e.g., "3 x 5", "8+2") and all other problems were considered large (e.g., "7 x 8", "9+6"). This method results in an equal number of small and large problems. All combinations were used for both addition and multiplication problems, resulting in 
128 different problems. Each problem was presented twice, resulting in a total of 256 problems overall.

All operands and operation symbols $(+$ and $x)$ were presented in black 60 point Courier New font on a white background. For each problem the operation symbol was located at the center of the screen and each operand was located $80 \mathrm{~mm}$ on either side of the operation symbol. All problems were presented horizontally.

\section{Procedure}

Participants were tested individually, and an experimenter was present in the room during the entire experiment. Participants read and signed an informed consent form before beginning. The experimenter initiated the experiment, and instructions appeared on the screen indicating to participants that they would be presented with single-digit addition and multiplication problems. Participants were asked to state the solution aloud into a headset microphone as quickly as possible without sacrificing accuracy. The experimenter paraphrased the instructions if the participants were confused about the task (e.g., if participants thought they needed to type their responses into a keyboard).

Each trial began with a fixation point (square) appearing in the center of the screen for $500 \mathrm{~ms}$, followed by a blank screen for $250 \mathrm{~ms}$. The arithmetic problem appeared immediately thereafter. The problem remained on the screen until the voicekey trigger registered a response or until a maximum time of fifteen seconds. The problem disappeared immediately and the experimenter recorded the participant's response. The next trial began once the response was recorded. If the voice-key trigger registered a sound that was not a solution (e.g., a sharp breath, "umm"), if the 
voice-key trigger failed to register the first response, or if the trial timed out, the experimenter marked the trial as void instead of entering a response.

The problems were divided by operation and problem size, resulting in four types of problems: Small addition, large addition, small multiplication, and large multiplication. Problems were first grouped by operation and were presented to participants in an $\mathrm{AABBAABB}$ ordering; this results in half of the trials repeating operations and half of the trials switching operations, and reflects the procedure of a typical task switching paradigm (Kiesel et al., 2010). When operation repeated, problem size repeated as well, and every problem type occurred twice for every eight trials. For example, a participant might have solved two large addition problems, followed by two small multiplication problems, followed by two small addition problems, followed by two large multiplication problems. Eight sequences of problem type were created and counterbalanced across participants. The sequence remained consistent for each participant. As such, although the trials were not pre-cued they were predictable. See Appendix A for all sequences.

Once participants had completed all 256 problems, they completed a series of measures that were part of another study as well as a short questionnaire. Participants were then debriefed and invited to ask any questions before being dismissed.

\section{Results}

Response times, total error rates, and operation error rates were entered into separate 3 (Sequence: repeat, small switch, large switch) x 2 (Target Operation: addition, multiplication) $\times 2$ (Target Problem Size: small, large) ANOVAs. The sequence effect was split into two orthogonal contrasts: The switch effect compared 
repeat trials to the average of small switch + large switch trials and the $n-1$ size effect compared small to large switch performance $(n-1$ denotes the problem immediately prior to the target). Table 1 presents source tables for all corresponding three-way ANOVAs. See Table 2 for all response times, total errors, and operation errors.

\section{Response Time}

See Figure 1 for all median response times. Consistent with previous research (Campbell \& Xue, 2001) participants solved addition problems more quickly than multiplication problems (1293 vs. $1443 \mathrm{~ms}$ ). Consistent with existing research on the problem size effect (Ashcraft \& Guillaume, 2009; Zbrodoff \& Logan, 2005) participants solved small problems more quickly than large problems (1129 vs. 1607 ms). Additionally, there was an operation x problem size interaction in which the problem size effect was larger for multiplication problems than for addition problems (596 vs. $361 \mathrm{~ms}$ ).

Participants were also influenced by problem sequence. Participants solved repeat trials more quickly than switch trials (1329 vs. $1388 \mathrm{~ms}$ ), and also solved problems on switch trials more quickly when the preceding problem was small than when it was large (1364 vs. $1411 \mathrm{~ms})$. The operation switch effect did not differ for addition and multiplication, but the effect of $n-1$ problem size only occurred on addition problems. Switch costs were high when participants had to switch from a large multiplication problem to an addition problem but much smaller during any other type of switch. See Figure 2 for response times as a function of sequence and operation. 
Table 1. Source table for all three-way ANOVAs.

\begin{tabular}{|c|c|c|c|c|}
\hline & \multicolumn{2}{|c|}{ Response Time } & \multicolumn{2}{|c|}{ Errors } \\
\hline & $\begin{array}{l}\text { All Trials } \\
\text { Included }\end{array}$ & $\begin{array}{c}\text { Post-error Trials } \\
\text { Excluded }\end{array}$ & $\begin{array}{c}\text { Total } \\
\text { Errors }\end{array}$ & $\begin{array}{c}\text { Operation } \\
\text { Errors }\end{array}$ \\
\hline Operation (F) & $10.0^{* *}$ & $12.5^{* *}$ & $44.7^{* * *}$ & 2.9 \\
\hline MSE & 410123 & 326430 & 168 & 0.2 \\
\hline$\eta_{p}^{2}$ & .14 & .17 & .43 & .05 \\
\hline Problem Size (F) & $119.1^{* * *}$ & $104.2^{* * *}$ & $73.5^{* * *}$ & $9.9^{* *}$ \\
\hline MSE & 351844 & 399052 & 193 & 0.1 \\
\hline$\eta_{p}^{2}$ & .67 & .63 & .55 & .14 \\
\hline Sequence $(F)$ & $6.4^{* *}$ & $6.3^{* *}$ & 1.3 & 1.9 \\
\hline MSE & 63155 & 72920 & 36.4 & 0.1 \\
\hline$\eta_{p}^{2}$ & .10 & .10 & .02 & .03 \\
\hline Switch Contrast (F) & $8.4^{* *}$ & $15.7^{* * *}$ & 3.2 & $5.9^{*}$ \\
\hline MSE & 65861 & 51123 & 28 & 0.01 \\
\hline$\eta_{p}^{2}$ & .12 & .21 & .05 & .09 \\
\hline n-1 Size Contrast (F) & $4.3^{*}$ & 1.2 & $<1$ & $<1$ \\
\hline MSE & 60449 & 94718 & 45 & 0.01 \\
\hline$\eta_{p}^{2}$ & .07 & .02 & $<.01$ & $<.01$ \\
\hline Op $\times$ PS (F) & $11.8^{* *}$ & $11.1^{* *}$ & $53.2^{* *}$ & $5.4^{*}$ \\
\hline MSE & 213810 & 203176 & $119^{\circ}$ & 0.1 \\
\hline$\eta_{p}^{2}$ & .16 & .16 & .47 & .08 \\
\hline $\mathrm{Op} \times \mathrm{Sq}(\mathrm{F})$ & $3.5^{*}$ & 2.1 & 2.4 & 2.3 \\
\hline MSE & 66897 & 60970 & 47 & 0.1 \\
\hline$\eta_{p}^{2}$ & .06 & .03 & .04 & .04 \\
\hline Op x Switch (F) & 2.3 & $<1$ & 3.9 & $<1$ \\
\hline MSE & 68298 & 55090 & 37 & 0.01 \\
\hline$\eta_{p}{ }^{2}$ & .04 & .01 & .06 & $<.01$ \\
\hline Op $\times n-1$ Size $(F)$ & $4.7^{*}$ & 3.4 & 1. & 3.8 \\
\hline MSE & 65495 & 66851 & 56 & 0.01 \\
\hline$\eta_{p}^{2}$ & .07 & .05 & .02 & .06 \\
\hline$P S \times S q(F)$ & $<1$ & 1.1 & $<1$ & 1.9 \\
\hline MSE & 45721 & 72195 & 42 & 0.1 \\
\hline$\eta_{p}^{2}$ & .01 & $<.01$ & $<.01$ & .03 \\
\hline Op x PS x Sq (F) & $<1$ & $<1$ & $<1$ & $<1$ \\
\hline MSE & 58909 & 67672 & 42 & 0.1 \\
\hline$\eta_{p}^{2}$ & .07 & $<.01$ & .02 & $<.01$ \\
\hline
\end{tabular}

Note. $d f=F(2,120)$ for tests involving the sequence factor, $d f=F(1,60)$ for all other tests.

${ }^{*} p<.05, * * p<.01, * * * p<.001$. 
Table 2. Median response times, mean total error rates, and mean operation error rates on target trials for all conditions.

\begin{tabular}{|c|c|c|c|}
\hline & \multicolumn{3}{|c|}{ Type of Trial (n-1 Trial) } \\
\hline & Repeat Trial & n-1 Small & n - 1 Large \\
\hline & \multicolumn{3}{|c|}{ Response Time (ms) } \\
\hline Small Addition & 1046 & 1100 & 1193 \\
\hline Large Addition & 1422 & 1450 & 1550 \\
\hline Small Multiplication & 1106 & 1162 & 1167 \\
\hline \multirow[t]{2}{*}{ Large Multiplication } & 1743 & 1747 & 1733 \\
\hline & \multicolumn{3}{|c|}{ Response Time with Post-error Trials Excluded (ms) } \\
\hline Small Addition & 1034 & 1087 & 1168 \\
\hline Large Addition & 1414 & 1452 & 1519 \\
\hline Small Multiplication & 1095 & 1163 & 1146 \\
\hline \multirow[t]{2}{*}{ Large Multiplication } & 1685 & 1744 & 1737 \\
\hline & \multicolumn{3}{|c|}{ Total Error Rates (\%) } \\
\hline Small Addition & 4.0 & 5.0 & 4.0 \\
\hline Large Addition & 8.0 & 7.0 & 7.0 \\
\hline Small Multiplication & 4.0 & 4.0 & 6.0 \\
\hline \multirow[t]{2}{*}{ Large Multiplication } & 18.0 & 20.0 & 20.0 \\
\hline & \multicolumn{3}{|c|}{ Operation Error Rates (\%) } \\
\hline Small Addition & 2.2 & 2.5 & 2.0 \\
\hline Large Addition & 0.5 & 1.4 & 0.9 \\
\hline Small Multiplication & 1.1 & 0.7 & 1.6 \\
\hline Large Multiplication & 0.5 & 1.0 & 1.3 \\
\hline
\end{tabular}




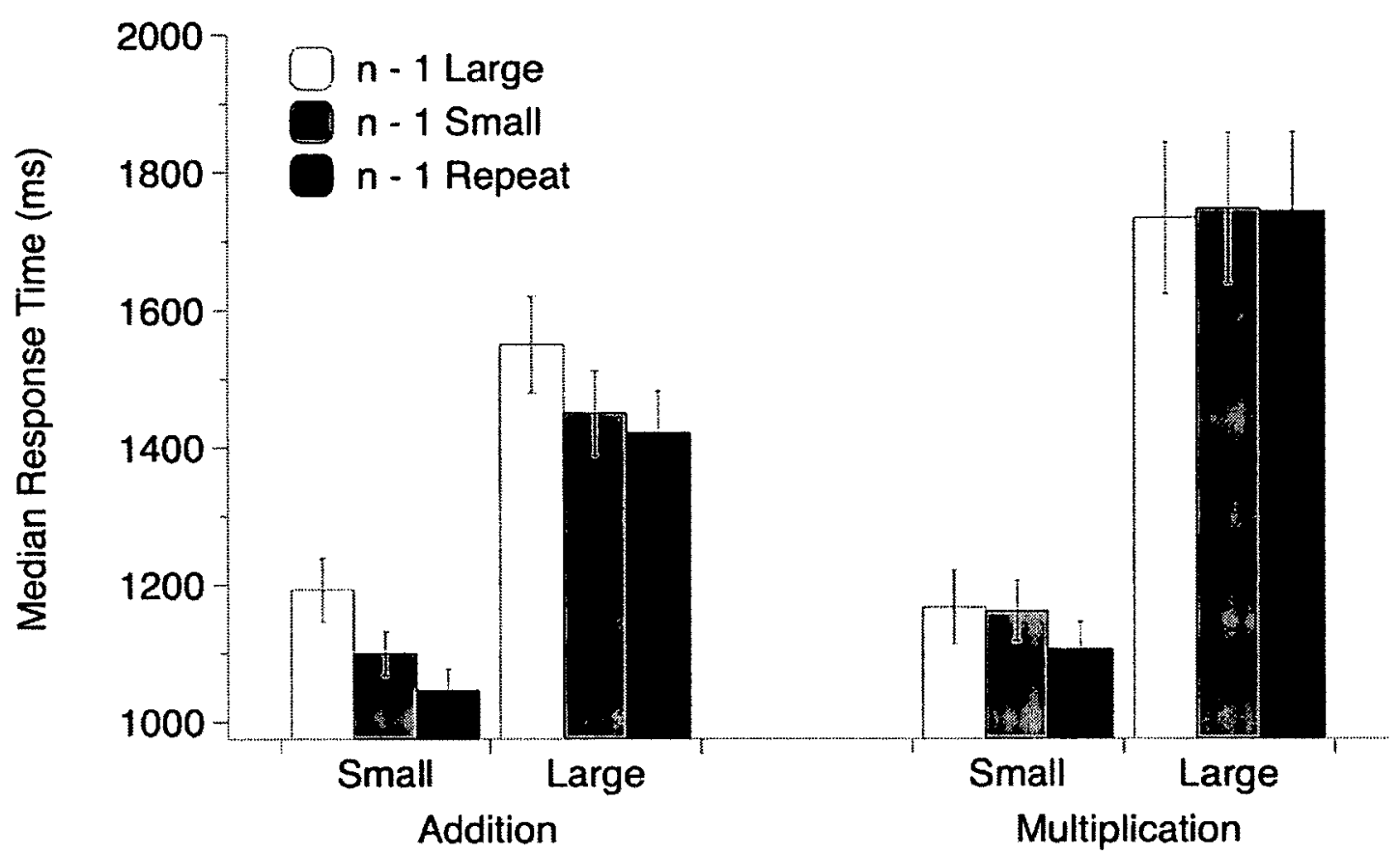

Figure 1. Response time as a function of sequence, operation, and problem size. Error bars represent $95 \%$ confidence intervals calculated according to the methods described in Masson and Loftus (2003) and Jarmasz and Hollands (2009).

\section{Error Rates}

The effects of operation and problem size on error rates were parallel to the effects on response time. Participants made fewer errors on addition problems than on multiplication problems ( $6 \%$ vs. $12 \%$ ) and made fewer errors on small problems than on large problems (4\% vs. $13 \%$ ). Additionally, the problem size effect was much larger for multiplication problems than for addition problems (14\% vs. $3 \%)$. Participants did not make any more errors on switch than on repeat trials, making errors on approximately $9 \%$ of the problems in all conditions. Thus, accuracy was apparently not influenced by switch costs. 


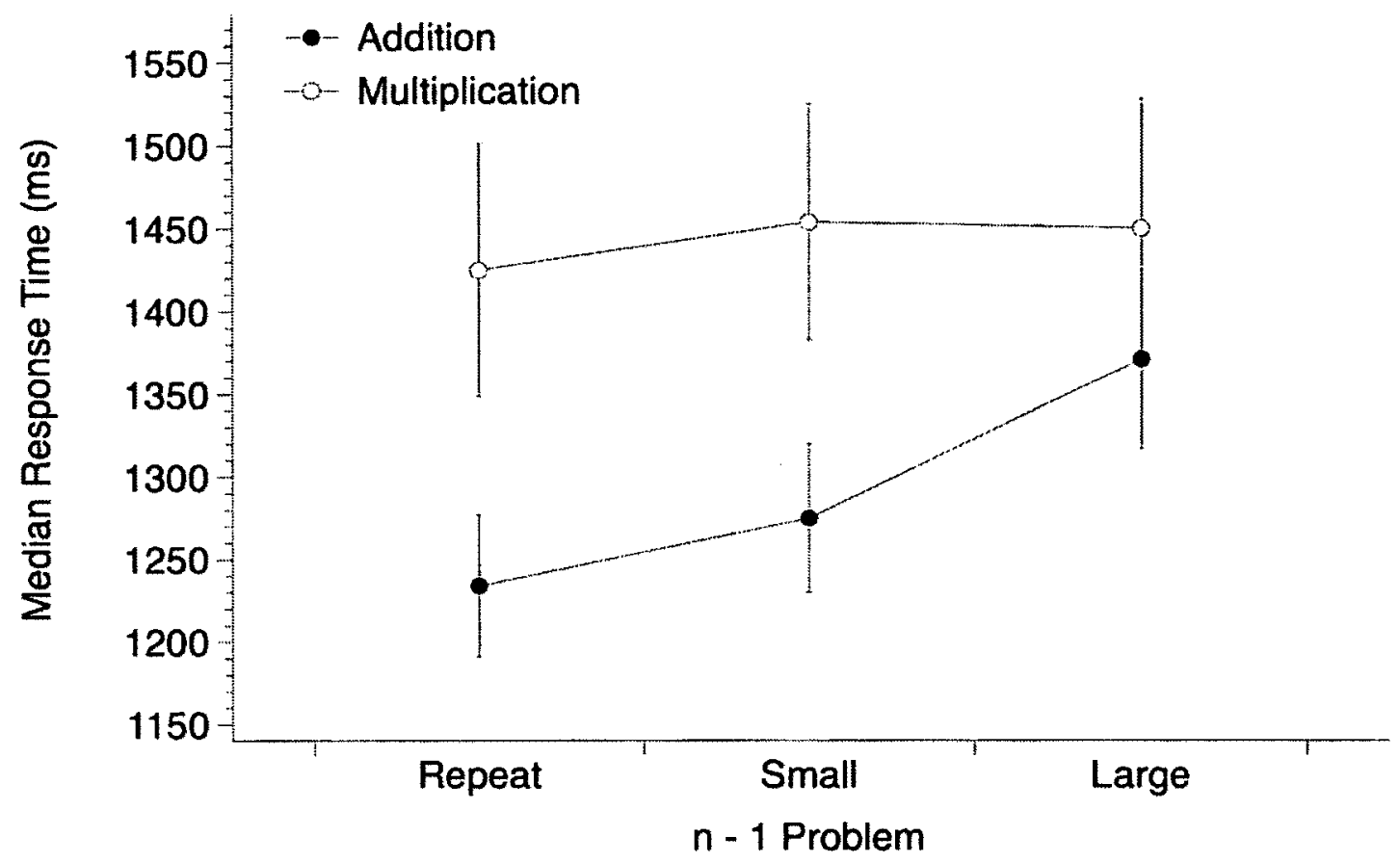

Figure 2. Response time as a function of sequence and operation. Error bars represent $95 \%$ confidence intervals calculated according to the methods described in Masson and Loftus (2003) and Jarmasz and Hollands (2009).

\section{Operation Error Rates}

Operation errors were low overall ( $1.4 \%$ of problems). However, following Campbell and Arbuthnott (2010), the percentage of operation errors across all trials was analyzed in a three-way ANOVA as above. Participants made more operation errors on small problems than on large problems ( $1.7 \%$ vs. $1.0 \%)$. This effect was qualified by an operation $\mathrm{x}$ problem size interaction where participants made more operation errors on small addition problems $(2.2 \%)$ than on large addition problems or small and large multiplication problems $(1.0 \%, 1.2 \%$, and $0.9 \%)$. Additionally, 
operation error rates were higher on switch trials (1.4\% from small problems, $1.5 \%$ from large problems) than on repeat trials (1.1\%). Thus, consistent with Campbell and Arbuthnott, there is some indication that operation errors are more likely when participants switch between operations. The switch costs did not interact with operation, however.

These results are consistent with Campbell and Arbuthnott (2010). However, the asymmetric switch costs on response times might not be entirely due to switching effects. Instead, the high switch costs may have been exacerbated because of an effect of slowing following an error. Participants made many more errors on large multiplication problems compared to all other types of problems (i.e., $19 \%$ vs. a mean of $5 \%$ ) and the largest switch cost was found following large multiplication problems. Participants tend to slow down immediately following an error, in cognitive tasks generally (e.g., Brewer \& Smith, 1984; Notebaert et al., 2009; Rabbitt, 1979) as well as in arithmetic verification specifically (Desmet et al., in press). A paired-samples $t$ test between trials following a correct response and trials following an error (post-error trials) tested for an effect of post-error slowing. As expected, participants were slower immediately following an error compared to following a correct response (1702 vs. $1265 \mathrm{~ms}), t(60)=2.78, p=.012$, introducing the possibility that switching from large multiplication problems might have produced high costs due to a higher rate of errors.

Campbell and Arbuthnott also considered the possibility that post-error slowing contributed to switch costs and re-ran their analyses excluding post-error trials. They reported that there was still a reliable interaction between operation and $\mathrm{n}$ -1 problem size. However, the error rates in the current experiment were higher than 
in Campbell and Arbuthnott's experiment. Participants made 1.8\% more errors overall, and importantly they made $5.2 \%$ more errors on large multiplication problems. In the current experiment post-error slowing might have played a larger role than in Campbell and Arbuthnott, exacerbating the asymmetric switch costs. Thus, I reanalyzed the data to exclude trials that followed an error.

\section{Post-error Trials Excluded}

See Figure 3 for all median response times after post-error trials were excluded. The effects of operation and problem size remained largely unchanged. Participants still solved addition problems faster than multiplication problems (1279 vs. $1428 \mathrm{~ms}$ ) and solved small problems faster than large problems (1115 vs. 1592 ms). The problem size effect was also larger for multiplication problems than for addition problems (588 vs. $366 \mathrm{~ms}$ ).

Participants still solved switch trials more slowly than repeat trials (1377 vs. $1307 \mathrm{~ms}$ ). However, participants no longer seemed to be influenced by the size of the preceding problems, $p=.27$. Consistent with the previous analysis, switch costs were equivalent for addition and multiplication. The interaction between the $n-1$ size contrast and operation approached significance, $p=.07$. Although this is not a reliable effect, the presence of a marginal effect suggests that the asymmetric switch costs following large multiplication problems cannot confidently be attributed entirely to post-error slowing. See Figure 4 for response times as a function of sequence and operation. 


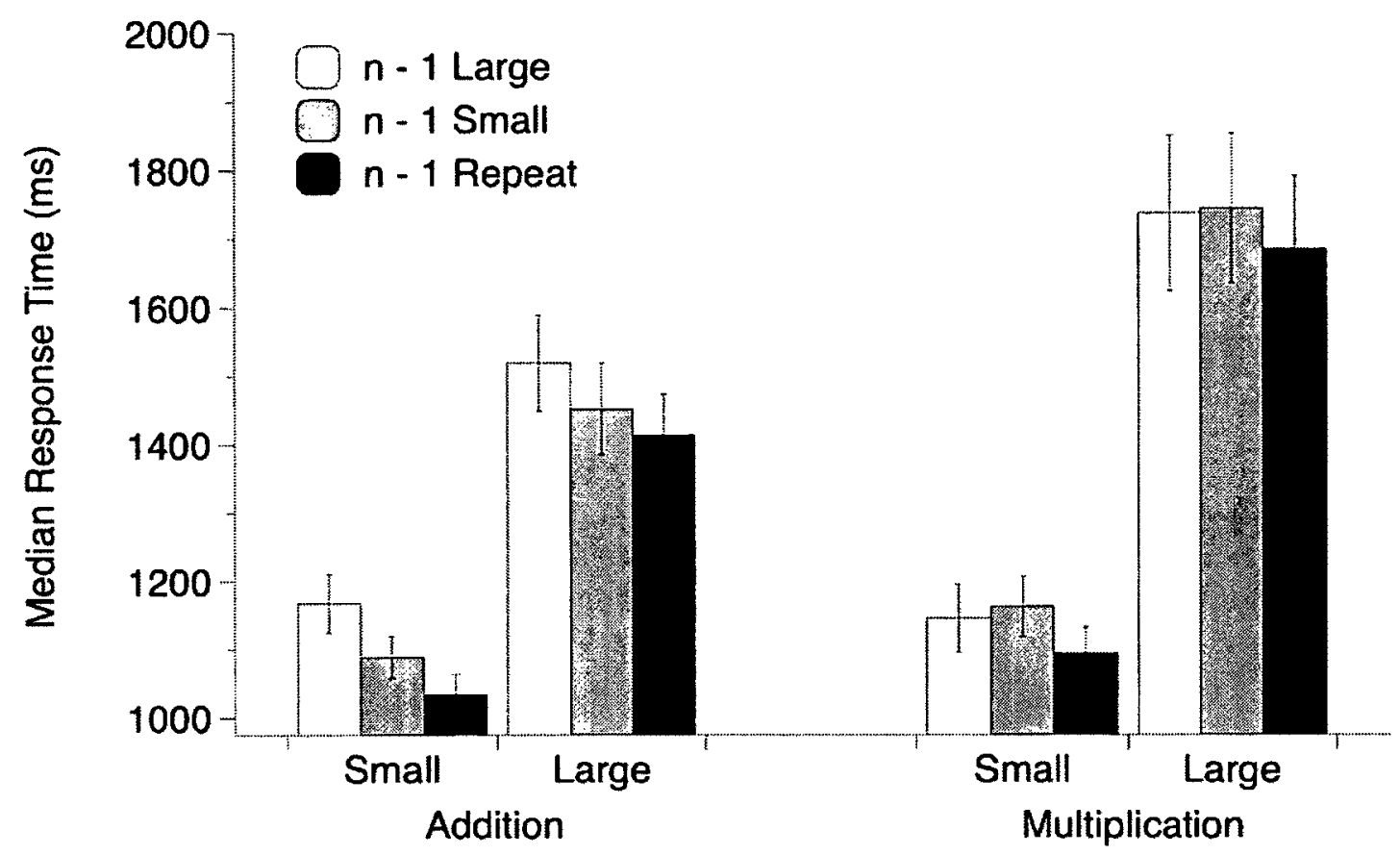

Figure 3. Response time as a function of sequence, operation, and problem size, posterror trials excluded. Error bars represent $95 \%$ confidence intervals calculated according to the methods described in Masson and Loftus (2003) and Jarmasz and Hollands (2009).

When post-error trials were excluded, the overall switch cost was actually higher than when post-error trials were included (70 vs. $58 \mathrm{~ms}$ ). However, this is primarily due to a marked increase in the switch costs for multiplication problems, especially large problems. This pattern is discussed in more detail in the Discussion section. However, excluding post-error trials decreased switch costs on the trials of interest, namely when large multiplication problems preceded addition problems. When post-error trials were included, switch costs following large multiplication problems were $138 \mathrm{~ms}$. When post-error trials were excluded, switch costs following 
large multiplication problems were $120 \mathrm{~ms}$. Thus removing post-error trials decreased switch costs from large multiplication problems by approximately $13 \%$, suggesting that post-error slowing did contribute to asymmetrical switch costs.

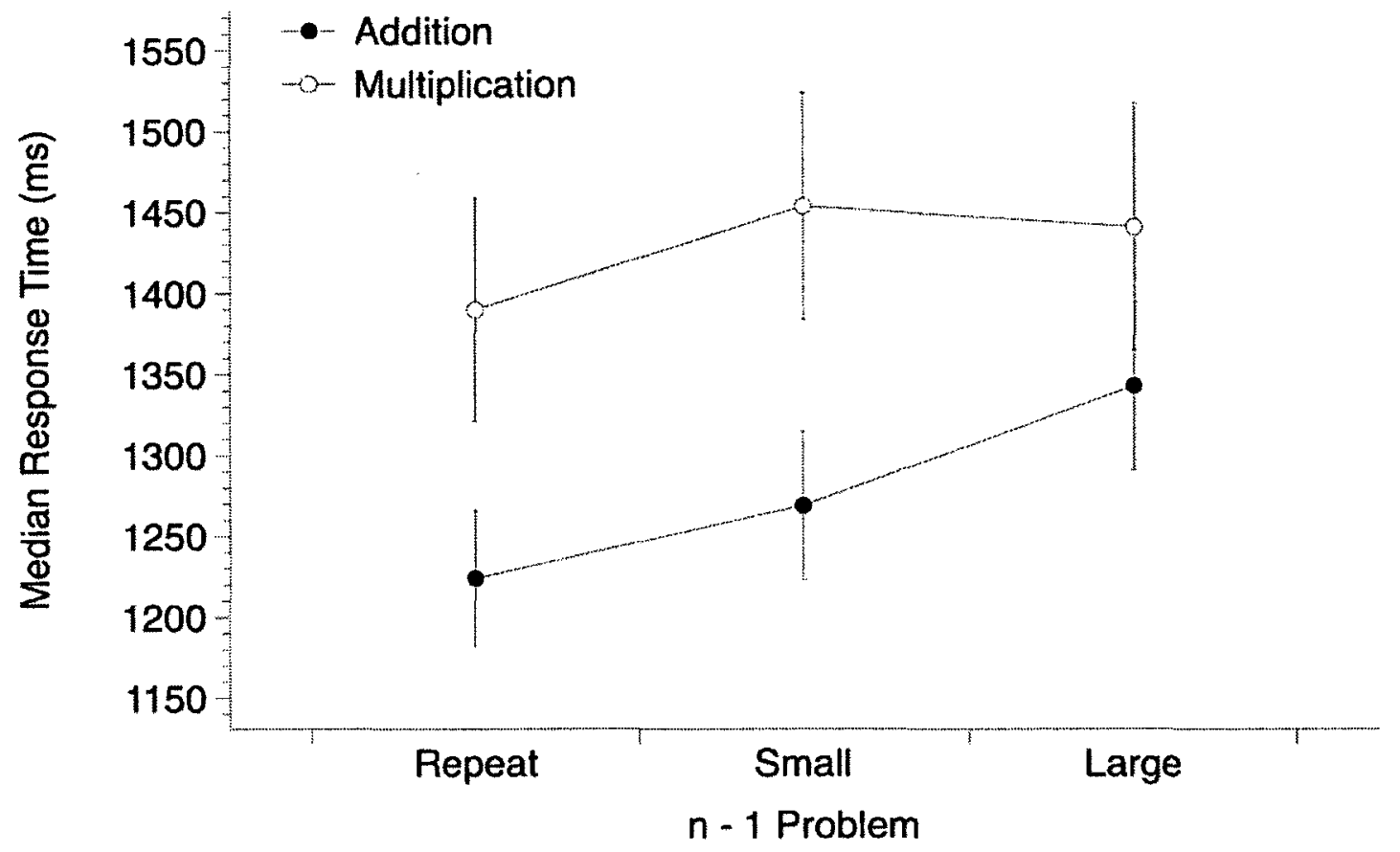

Figure 4. Response time as a function of sequence and operation, post-error trials excluded. Error bars represent $95 \%$ confidence intervals calculated according to the methods described in Masson and Loftus (2003) and Jarmasz and Hollands (2009). 


\section{Discussion}

Participants solved single-digit addition and multiplication problems in alternating runs of two (e.g., addition, addition, multiplication, multiplication). Consistent with past research (Campbell \& Xue, 2001) participants solved addition problems more quickly and more accurately than they solved multiplication problems. Participants also demonstrated a typical problem size effect (Zbrodoff \& Logan, 2005) in which they solved small problems more quickly and accurately than large problems. According to an operational definition of difficulty, large multiplication problems were the most difficult problems, followed by large addition problems, small multiplication problems, and finally small addition problems. These findings show that performance in this experiment showed typical effects of operation and problem size found in a wealth of previous research (e.g., Campbell \& Xue, 2001; Ashcraft \& Guillaume, 2009; Zbrodoff \& Logan, 2005).

As hypothesized, participants' performance was also sensitive to the trial-bytrial sequence: They solved problems more quickly on repeat trials, where the same operation occurred on the previous trial, than on switch trials where the alternative operation occurred on the previous trial. Furthermore, participants were slower to respond following a large problem compared to a small problem, and this pattern was independent of the size of the target problem. However, the switch cost was qualified by the operation of the target problem. The switch cost was large when the target problem was addition: Both small and large addition problems were solved fastest on repeat trials and slowest following a large multiplication problem, demonstrating an 
overall switch cost effect as well as an asymmetrical difficulty-related switch cost. In contrast, but consistent with Campbell and Arbuthnott (2010), multiplication problems were uninfluenced by the size of the preceding addition problem.

Participants were also slower following a trial on which they made an error. Because large multiplication problems elicited both the lowest accuracy rates and the highest switch costs, post-error trials were removed to eliminate post-error latency costs as a potential influence on switch costs. The overall pattern of effects was similar to the results with error trials included but there were some qualitative differences. Although there was still some evidence for switch costs on addition problems, the effect was smaller with post-error trials removed. Furthermore and surprisingly, the switch costs for multiplication were larger after post-error trials were removed (58 vs. $28 \mathrm{~ms})$.

In the rest of the Discussion section, task switching is discussed in further detail, framing the current results within predominant theories of this phenomenon. Three potential sources of arithmetic operation switch costs are discussed: Interference between representations in networks of arithmetic facts, interference between cognitive procedures used to solve problems, and slowing due to post-error effects.

\section{Task Switching}

There are a number of theories of task switching (see Kiesel et al., 2010). Despite differences, most theories are centered on the concept of a task set. A task set is a combination of cognitive procedures or processes and mental representations that are required to perform a certain task. For example, the task set for mental arithmetic requires mental representations of the problems as well as the variety of cognitive 
procedures that can be used to produce the answer. However, different operations require different problem representations (e.g., $3+4$ and $3 \times 4$ are different because their problem nodes contain different solutions). Additionally, different operations can be solved using different procedures (e.g., counting up by ones does not help a participant solve a multiplication problem). Thus, addition and multiplication require different, albeit similar, task sets. In order to solve an arithmetic problem, the appropriate operation task set must be activated. The multiplication task set is weaker than the addition task set for two primary reasons. First, the representations of the multiplication facts have lower memory strength than the representations of addition facts. Retrieving 10 from $4+6$ is much easier than retrieving 24 from $4 \times 6$. Second, when retrieval fails and procedures are used, the procedures used in multiplication are less automatic than the procedures used in addition. For example, counting up by ones is a well-learned sequence. However, counting up by larger numbers such as sixes or sevens is far less practiced.

Many accounts of task switching describe switch costs as a process of task-set reconfiguration (e.g., Meiran, 1996; Monsell \& Mizon, 2006; Rogers \& Monsell, 1995). On the reconfiguration view, a certain amount of time and effort is required to adequately activate a task set. When the required task switches on a new trial, participants must activate the appropriate task set. The activation process is assumed to account for the increase in response time that is typically observed. Evidence for this account comes from the observation that, in cued task-switching experiments, increasing the time between presentation of the cue and the target stimulus results in lower switch costs. Presumably the extra time allows task reactivation to occur before 
the target appears. Because, however, switch costs do not disappear completely even with long intervals, researchers have proposed a two-stage reconfiguration model where the task set cannot be entirely reconfigured until the stimulus is presented, accounting for the remaining switch cost (Mayr \& Kliegl, 2000, 2003; Rubinstein et al., 2001).

Although the reconfiguration model is plausible and accounts for some aspects of the patterns observed in task switching experiments, it does not easily explain switch cost asymmetries. If switch costs only reflect a reconfiguration process then switching from a difficult to an easy task should take less time that switching from an easy to a difficult task, because the task set for an easy task will be less complex and have higher baseline activation. However, the empirical evidence in previous research as well as the current work clearly support switch cost asymmetries. Thus, the reconfiguration model cannot be a complete account of task switching.

An alternative account of task switching proposes that task sets interfere with each other (e.g., Allport, Styles, \& Hsieh, 1994; Allport \& Wylie, 1999; Wylie \& Allport, 2000). On the interference view, task sets are still activated in order to perform the appropriate task, but the activation decays gradually and as such it persists from trial to trial. On repetition trials this residual activation is not problematic, and may be beneficial to performance. However, on switch trials, a new task set must be activated. The activated task set from the previous trial proactively interferes with the new task set and the amount of interference depends on the degree of activation of that old task set. The need to overcome this interference produces switch costs. These task-set inertia theories account for switch cost asymmetries. Difficult tasks require 
higher levels of activation to perform than easier tasks, due to different baseline activation levels (Gilbert \& Shallice, 2002; Yeung \& Monsell, 2003). Additionally, it might also be the case that the easier task, which is often at least partially automatic, must be inhibited while performing the difficult task (e.g., Arbuthnott, 2008). Together, the high levels of activation for the difficult task and the inhibition of the easy task interfere with subsequent performance of the easy task.

There is ample evidence that interference is important in mental arithmetic (e.g., Arbuthnott \& Campbell, 1994; Campbell, 1995; Verguts \& Fias, 2005; Zbrodoff \& Logan, 1986), and some evidence that inhibitory processes play a role as well (e.g., Arbuthnott \& Campbell, 2000, 2003; Campbell \& Thompson, 2012). As such, the task-set inertia accounts of task switching seem readily applicable to mental arithmetic. However, an alternative theory presents some interesting applications as well. Logan and colleagues have advocated an account of task-switch asymmetries based on differences in cue encoding. They point out that, at least in cued taskswitching experiments, task switches are confounded with cue switches (Schneider \& Logan, 2005). In order to separate the two factors, they provided two cues to indicate each task (2:1 cue-task mappings). With 2:1 mappings, trials can switch tasks and cues independently. Across many experiments (Logan \& Schneider, 2006; Schneider \& Logan, 2006a, 2007, 2009, 2011; Logan, Schneider \& Bundensen, 2007), the consistent finding is that cue switches produce switch costs similar in magnitude to a combined cue and task switch. Schneider and Logan (2005) suggest a model in which the cue and target are both encoded and then combined into a cue-target compound. This compound is used to retrieve the necessary response. Switch costs are produced 
because on task repetitions there is a benefit of encoding the same cue as on the previous trial.

Although in the current experiment arithmetic operation was not pre-cued, the operation sign necessarily acted as a cue, because any combination of operands could occur with both addition and multiplication. Furthermore, because arithmetic problems are often solved via direct retrieval (Campbell \& Xue, 2001; LeFevre et al., 1996; LeFevre, Sadesky, \& Bisanz, 1996), the cue-encoding account of task switching seems highly appropriate due to its emphasis on retrieval from long-term memory. In the following discussion, both the task-set inertia and cue-encoding theories of task switching will be considered. It is likely that task switching reflects processes described by both theories (Arrington, Logan, \& Schneider, 2007).

\section{Network Interference}

It is clear that arithmetic facts, both within and across operations, can interfere with each other. In multiplication, incorrect responses are usually table-related (e.g., 4 x $7=21$; that is, the correct answer to a related problem; Campbell \& Graham, 1985). Practicing retrieval of specific multiplication facts reduces retrieval efficiency for the corresponding addition problem with the same operands (Campbell \& Thompson, 2012). Finally, the work presented here (also Campbell \& Arbuthnott, 2010; Miller \& Paredes, 1990) suggests that switching between operations is difficult. Arithmetic problems are most often solved via retrieval, and as such switch costs will first be considered under the assumption that solutions are being retrieved on adjacent trials.

If problems are solved via retrieval, the task set for arithmetic only contains one cognitive process. The differences in performance, then, must reflect differences 
in the mental representations of the arithmetic facts. Addition solutions, especially for small problems, have very high memory strength and are retrieved quickly. On the other hand, large multiplication problems are not represented strongly in memory and require much more time to retrieve. When an arithmetic solution is retrieved, activation automatically spreads throughout the network of facts to related problems that share common components (Campbell, 1994, 1995). For example, when a small addition problem such as $3+2$ is presented, the associated problem node, $\{3,2,+, 5\}$, is activated. However, related problems such as $3+4,4+2$, and $3 \times 2$ are also activated. Because $3+2$ is represented strongly in memory, its baseline activation is high and it is retrieved quickly. As such, the related solutions are only activated for a short period of time. In contrast, consider a problem such as $8 \times 7$. Especially for low-skilled adults, the memory strength of the associated problem node is very low. As such, it takes longer for the problem node to be sufficiently activated for retrieval, and related problems are activated for a longer period of time.

Switching between a small addition problem and a large multiplication problem should not produce much interference, and thus switching operations should not produce high performance costs. When a small addition problem is solved, activation only spreads to competing solutions for a short period of time and as a result the competing solutions only have slightly elevated activation on the next trial. The increased interference produced by these problems on the next trial is minimal. However, when a large multiplication problem is solved, activation has spread to competing facts for a much longer period of time. On the next trial, these problems have a much higher level of activation and thus interfere with retrieval of the next 
problem strongly. The persistent activation from a difficult problem had a clear effect in the current experiment, increasing response times by between 120 and $140 \mathrm{~ms}$ on average.

Although differences in activation requirements seem to play a clear role, inhibitory processes have also been demonstrated in both mental arithmetic (Arbuthnott \& Campbell, 2000, 2003) and task switching (e.g., Allport, Styles, \& Hsieh, 1994; Allport \& Wylie, 1999; Wylie \& Allport, 2000). However, evidence for inhibitory processes is not clearly present in the current experiment. An inhibition account of arithmetic task switching predicts large switch costs between problems with high memory strength. Consider a problem such as $2 \times 4$. This problem has very high memory strength and therefore high baseline activation in memory. However, the associated problem $2+4$ also has high baseline activation. In many cases $2+4$ might reach sufficient activation before $2 \times 4$ does, in which case $2+4$ needs to be inhibited to avoid responding " 6 ". On a subsequent addition problem, the baseline activation of the problem might be lower and therefore more time is required for retrieval. If inhibitory processes played a role in switch costs in the current experiment, there should be high switch costs between small addition and small multiplication problems, which typically have high memory strength. Although participants demonstrated a switch cost between these problems, the costs were not any higher than costs between other types of problems. They were certainly much lower than switch costs following large multiplication problems. Therefore the present data suggest that, in the case of mental arithmetic, the difficulty-related switch 
cost asymmetry needs to be linked to the activation requirements for difficult problems rather than to inhibition of easy problems.

Describing asymmetric switch costs in terms of memory strength rather than inhibition is consistent with the cue-encoding account of task switching (Schneider \& Logan, 2005). The target (operands) and the cue (operation sign) are presented together and encoded into a compound cue. The compound cue is used to retrieve the correct response from long-term memory. In mental arithmetic, the problem, which includes the target and the task cue, serves as a compound cue to retrieve the solution. The retrieval processes are subject to the same activation requirements proposed by the task-set inertia account, and therefore the task-set inertia and cue-encoding theories make consistent predictions when arithmetic problems are retrieved.

Task switching experiments provide an opportunity to further examine the processes behind arithmetic fact retrieval. In current models of arithmetic (Campbell, 1995; Verguts \& Fias, 2005a) activation spreads to related problems, but details regarding this spreading are unclear. One particularly important question is whether retrieving a problem only activates related problems or if activation spreads throughout the network more generally. Arithmetic fact inhibition has been proposed to be specific to particular problems (e.g., Campbell \& Thompson, 2012) as well as more generally applied to the entire network (e.g., Miller \& Paredes, 1990). The current data cannot distinguish the two accounts. However, the task switching paradigm might be able to provide further insights. A future experiment might restrict the problems presented in each operation so that problems related to each other do not occur in both operations. If activation only spreads to related problems then when the 
operation switches there should be little interference between problems. Thus high switch costs should not be observed. In contrast, if activation spreads throughout the network more generally, problems will compete with each other even if they are not related and high switch costs should still be observed.

In summary, when the preceding problem is difficult and takes a long time to retrieve, activation has more time to spread to other problems. On the target trial, the recently activated problems are highly activated and interfere with retrieval of the correct problem. Because large multiplication problems are solved much more slowly than any other problem type, an account of switch costs based on network interference predicts asymmetrically large switch costs following large multiplication problems.

\section{Procedural Strategy Differences}

Arithmetic problems are not always solved via retrieval (LeFevre, Bisanz, et al., 1996; LeFevre, Sadesky, \& Bisanz, 1996). This fact introduces an interesting complication compared to previous research in task switching. In many experimental tasks commonly used in task switching research, there is generally not any strategy variation for any given task. For example, it seems unlikely that adult participants rely on a variety of strategies to read a word or name a colour. However, adults can and do employ a number of strategies for solving arithmetic problems. Three important points merit discussion. First, the task sets for addition and multiplication not only include different mental representations, but also different solution procedures. For example, the nines rule cannot be applied to addition problems (with the possible exception of $9+9$ ). Second and in contrast, many of the cognitive processes overlap and can be applied independently to each operation (e.g., transformation to a known 
fact). Although in the current experiment addition and multiplication are defined as the two "tasks", some cognitive processes can be applied to each operation. Schneider and Logan (2006b) have demonstrated that task sets can be hierarchical, where task sets are components of larger task sequences. A similar claim might be made regarding mental arithmetic. Addition and multiplication constitute their own task sets, but within those sets there are smaller component task sets such as long-term memory retrieval, counting, and transformation. Therefore a switch trial might actually draw upon the same component task set as the previous trial (addition retrieval; addition retrieval), switch operation but not procedure (multiplication retrieval, addition retrieval), or invoke a switch both of operation and procedure (multiplication transformation, addition retrieval). Lemaire and Lecacheur (2010) showed that participants demonstrate a switch cost when they switch strategies in a computational estimation task. Switching between procedures in arithmetic production might also produce a switch cost independently of switching operation.

Third and perhaps most importantly, proportions of procedural strategy use vary across operation and problem size. Procedures are more commonly used on more difficult problems, and this is especially true as problem size increases. Large addition and multiplication problems are solved using procedural strategies rather than retrieval more often than small problems. Procedural strategies are slower and might be less automatic than retrieval (Siegler, 1988, 1989; Siegler \& Shrager, 1984), so it might be the case that switching from a procedure to retrieval produces an asymmetrically large switch cost. The finding that large multiplication problems produce high switch costs on small addition problems is consistent with this hypothesis. However, the 
hypothesis also predicts a large switch cost from large addition problems (often solved using procedures) to small multiplication problems (often retrieved directly). However, the data in the current experiment did not support the hypothesis. The switch cost from large addition problems to small multiplication problems was not any higher than the average switch cost.

The data do not, however, entirely discount the procedural strategy hypothesis. One possibility is that the procedures typically used in large addition are represented by stronger task sets than the procedures used in large multiplication. Consider counting strategies used in each operation. Counting in addition follows the welllearned number sequence (by ones). However, counting in multiplication often requires counting by a less well-learned sequence (e.g., " $6,12,18,24,30$ "). Although counting in addition is slower than retrieval (LeFevre, Sadesky, \& Bisanz, 1996), counting in multiplication is likely more difficult. It might be the case that the wellpracticed procedures used for large addition problems are not as differentially difficult compared to retrieval, making any asymmetric switch costs difficult to detect statistically. This claim is supported by latency data from LeFevre, Bisanz, et al., 1996 and LeFevre, Sadesky, and Bisanz (1996). In LeFevre, Sadesky, and Bisanz, participants were $331 \mathrm{~ms}$ slower on average when using procedures compared to retrieving the solution for addition problems. In LeFevre et al., participants were 738 ms slower when using procedures compared to retrieving the solution for multiplication problems. Thus the difference in difficult between addition procedures and retrieval might not have been high enough to produce reliable asymmetric switch costs. 
The data from the current experiment do not necessarily support the procedural strategy hypothesis because procedure use was not recorded. Although switching procedures has been shown to produce costs in estimation (Lemaire \& Lecacheur, 2010), it is unclear whether procedure switch costs extend to exact arithmetic. It is not fully understood whether procedures are less automatic than retrieval. If procedures are typically used as a backup strategy when retrieval fails (Siegler \& Shrager, 1984) then procedures are likely to be less automatic than retrieval and thus switching procedures should produce switch costs. However, if retrieval and alternative procedures are both associated with an arithmetic problem, then they are both activated automatically (Shrager \& Siegler, 1998). In this case switching procedures should not produce switch costs. In order to test these contrasting hypotheses, future experiments might examine the procedures participants use to solve each problem; however this task seems challenging. Arithmetic experiments have historically examined strategy use via self-reports (LeFevre et al., 1996; LeFevre, Sadesky, \& Bisanz, 1996) and the operation-recognition paradigm (Thevenot, Fanget, \& Fayol, 2007). Despite their demonstrable validity, implementing either in a task switching experiment is very problematic (see Metcalfe \& Campbell, 2011). Instructing participants to either report a strategy or recognize an operand after each arithmetic problem introduces a new task between problems. This new task may therefore obscure any effects of task switching in arithmetic. First, each arithmetic problem would in reality be preceded by a non-arithmetic problem, producing task-switching effects that are irrelevant to switching operations. Second, switch costs typically only last one trial (Monsell et al., 2002; Rogers \& Monsell, 1995), suggesting that the 
transient interference from the previous task is eliminated once the new task is properly engaged. The short-lived nature of switch costs eliminates the possibility of measuring any residual switch cost from trial $n-2$. Third, research on $n-2$ switch costs predicts that operation repetitions will be slower than operation switches because performance is worse on task $\mathrm{A}$ in $\mathrm{ABA}$ task sequences than a $\mathrm{CBA}$ task sequence, a phenomenon known as backwards inhibition (Arbuthnott, 2008). For these three reasons, documenting the effects of differential strategy selection in an arithmetic taskswitching experiment poses a difficult challenge. One possible strategy might be to instruct participants to use retrieval or procedures from trial to trial. If participants are able to follow these instructions, procedure use can be observed and the automaticity of arithmetic procedures can be examined further

In summary, although the hypothesis is speculative, it seems plausible that both differences in task-set activation requirements and differences in the proportion of procedural strategy use might contribute to arithmetic operation switch costs. Both possibilities predict an asymmetrically high switch cost following a large multiplication problem, and therefore both hypotheses are consistent with the current data.

\section{Post-error Slowing}

One major difference between the current experiment and Campbell and Arbuthnott (2010) is that the current experiment found a substantial effect of removing post-error trials, whereas Campbell and Arbuthnott found no such effect. However, as previously discussed, the participants in the current experiment made more errors than Campbell and Arbuthnott's participants, especially on large multiplication problems. 
Therefore asymmetric switch costs due to difficulty might be partially caused by posterror slowing. When post-error trials were removed from the current data, there was less evidence of a difficulty-related switch cost on addition problems although the overall switch cost was still robust; in fact, the effect size was almost twice that in the analysis with the post error trials. The interaction between sequence, $n-1$ problem size, and target operation was no longer significant. However, it was marginally so, and when addition problems were analyzed separately the $n-1$ size contrast was still significant. The analyses suggest that although post-error slowing did not completely account for the asymmetrical switch cost following large multiplication problems, post-error slowing did contribute to the overall magnitude of the effect. This finding might provide further insights into the task switching process in mental arithmetic.

Post-error slowing outside the realm of mental arithmetic has traditionally been attributed to mental processes that alter the nature speed-accuracy tradeoff (Brewer \& Smith, 1984, 1989; Rabbitt, 1979). In such conflict monitoring approaches, participants notice that they made an error and increase their response threshold (Botvinick, Braver, Barch, Carter, \& Cohen, 2001). This threshold adjustment causes participants to be more conservative before responding, consequently slowing their responses but also increasing the likelihood that they will respond correctly. However, empirical evidence for a post-error accuracy increase is inconsistent. Although some studies find a post-error accuracy increase (e.g., Laming, 1968; Danielmeier, Eichele, Forstmann, Tittgemeyer, \& Ullsperger, 2011) many studies fail to find an effect (e.g., Hajcak \& Simons, 2008; King, Korb, von Cramon, \& Ullsperger, 2010) and others find a post-error accuracy decrease instead (e.g., Fiehler, Ullsperger, \& von Cramon, 
2005; Rabbitt \& Rodgers, 1977). Response times, in contrast, reliably increase following an error.

Alternatively, Notebaert et al., (2009) proposed an alternative orienting account in which it is the infrequent nature of errors in an experiment that produce post-error slowing. The rarity of the error captures attention, which impairs both response time and accuracy on the next trial. However, there are two reasons to doubt the latter account. First, Desmet et al., (in press) found that in complex tasks such as arithmetic verification, participants consistently show a post-error accuracy increase. Such an accuracy increase is not predicted by the orienting account. Second, in the current experiment, errors were frequent, occurring on nearly one fifth of large multiplication problems. As such, in the case of mental arithmetic, the simple attentional effects proposed by the orienting account are unlikely to account for posterror slowing.

However, Desmet et al. (in press) also provide evidence against conflict monitoring accounts of post-error slowing. Conflict monitoring suggests that after a high conflict trial that requires a great degree of cognitive control (e.g., following an incongruent Stroop trial), performance should improve. Desmet et al. manipulated conflict by providing highly related distracter problems on trial n-1 (e.g., " $4 \times 7=$ 21 "). Performance did not substantially improve following these types of trials, failing to support the conflict adaptation hypothesis. Desmet et al. instead suggest that in complex tasks such as mental arithmetic, participants switch to a more accurate strategy at the expense of response time. 
The evidence for the strategy adaptation hypothesis is not strongly supported by the current data. Participants were slower following an incorrect response, but they did not demonstrate a post-error accuracy increase, $p=.95$. However, the data do not completely discount the strategy adaptation hypothesis. Although participants might have switched to a more accurate procedural strategy following an error, the strategies they employed might not have been efficient enough to produce a marked increase in accuracy. As will be discussed below, the participants in the current experiment were relatively low skilled arithmeticians, and this might have contributed to the lack of an accuracy increase following an error.

Unexpectedly, removing post-error trials resulted in evidence that multiplication problems were also subject to switch costs. Although response times were still similar to those in the overall analysis following a small or large addition problem, multiplication problems were solved more quickly on repeat trials than on switch trials when post-error trials were excluded. Why did removing post error trials reveal a switch cost for multiplication? One possibility is that removing post-error trials eliminated an experimental artifact that selectively increased the average response time on large multiplication repetitions. On repetition trials, both the operation and the problem size repeated. Therefore on repeat trials, large multiplication problems always followed large multiplication problems. Because many large multiplication problems were answered incorrectly, it follows that there might be a disproportionately large effect of post-error slowing on multiplication repetitions. This possibility can be partially confirmed by comparing response times with and without post-error trials. Median response times were $15 \mathrm{~ms}$ faster when 
post-error trials were excluded. However, large multiplication problems on repeat trials were solved $58 \mathrm{~ms}$ faster when post-error trials were excluded, compared to a next-highest value of $31 \mathrm{~ms}$ for large addition problems preceded by a large multiplication problem. Therefore excluding post-error trials produced a greater benefit for multiplication repetitions (mean of $35 \mathrm{~ms}$ ) than for addition repetitions (mean of $10 \mathrm{~ms}$ ). This effect might have contributed to the increased switch cost for multiplication problems following the exclusion of post-error trials.

In summary, participants showed trial-by-trial switch costs (replicating Campbell \& Arbuthnott, 2010) when alternating between addition and multiplication. There was some evidence that participants solved addition problems more slowly following a large multiplication problem, demonstrating a difficulty-related asymmetrical switch cost for addition. This effect can plausibly be attributed to three sources: Differences in activation requirements and interference among problems, differences in the use of procedural strategies among problems, and differences between error rates among problems. In all three cases, large multiplication problems are predicted to produce the greatest deficit in performance on subsequent addition problems. Large multiplication problems require the longest period of activation to retrieve and therefore produce high levels of interference. Large multiplication problems are often solved by procedures that might be less automatic than retrieval. Finally, large multiplication problems are the most likely to be answered incorrectly. It is likely that all three of these factors contributed to the asymmetrical switch cost produced by large multiplication problems.

\section{Mathematical Fluency and Task Set Strength}


Although the overall pattern of results is qualitatively similar to the results found by Campbell and Arbuthnott (2010), there are clear quantitative differences in switch costs. Campbell and Arbuthnott found small switch costs, an average of approximately $20 \mathrm{~ms}$ in the uncued condition. The switch costs in the current experiment were much larger, approximately $64 \mathrm{~ms}$ overall. A likely explanation for the difference in switch costs is the difference in mathematical ability between the participants in Campbell and Arbuthnott's experiment and the participants in the current experiment. Campbell and Arbuthnott's data were collected in 1991 (Jamie Campbell, personal communication). It is well documented that university student population's mathematical skills have greatly declined since then (Mulhern \& Wylie, 2004). This claim can be corroborated by comparing the response times in Campbell and Arbuthnott with the response times in the current study. Campbell and Arbuthnott's participants solved problems with a mean latency of $1025 \mathrm{~ms}$ in uncued mixed blocks. In contrast, the participants in the current experiment solved problems in $1350 \mathrm{~ms}$, a $325 \mathrm{~ms}$ difference. The difference between the present participants and Campbell and Arbuthnott's participants on large multiplication problems was $613 \mathrm{~ms}$.

Clearly, the participants in the current study have far lower arithmetic abilities than the participants in Campbell and Arbuthnott. This low skill level is likely reflected in low memory strength for arithmetic facts as well as less efficient, and hence more effortful, use of procedures.

The combination of slow retrieval and increased use of procedures can be interpreted as the participants in the current study possessing weaker task sets for mental arithmetic than the participants in Campbell and Arbuthnott (2010). Weaker 
task sets can account for the much greater switch costs. A weaker task set requires more activation, the effect of which is twofold: First, activating a new task takes more time, making it difficult to switch tasks. Second, since a previously performed task required high levels of activation, there is more transient interfering activation on switch trials. Thus having lower arithmetic skill produces very high switch costs when multiple operations need to be performed. Because most task switching research uses tasks that are relatively simple and have little variability in performance (e.g., reading words and naming colours), not much is known about the influence of task ability on switch costs. However, Segalowitz and Frenkiel-Fishman (2005) demonstrated that switch costs between first and second language use in bilinguals decreased when second language fluency increased. Further, Censabella and Noel (2005) found that, in children, mixing costs decrease with higher mathematical fluency. The contrast in switch costs between the current data and Campbell and Arbuthnott replicate this pattern with adults and with local switch costs: Individuals with lower skill might experience greater switch costs.

An analysis of switch costs as a function of arithmetic fluency did not reveal any reliable pattern of results. However, very few participants in the present experiment were high skilled, making it difficult to split participants into groups based on fluency. Future research should actively seek low and high skilled participants to further examine the effect of arithmetic fluency on operation switch costs.

If arithmetic fluency does influence switch costs, there are broader implications for mathematical performance in general. Operation switches are more representative of real life situations than are single-operation experiments. Even in 
simple laboratory settings participants have demonstrated a consistent decline in mathematical performance. Given that this low mathematical ability also results in greater costs associated with switching operations, we might expect low-skilled mathematicians to show even greater deficits in mathematical situations outside the laboratory when multiple operations are required. Further examination of declining arithmetic task sets is important in this regard.

\section{Implications for Arithmetic Research}

The three proposed sources of the switch cost asymmetry each have implications for conducting research on mental arithmetic. First, although most experiments test operations in pure blocks of trials, it is important to note the general effect of interference between networks of arithmetic facts. Without controlling for asymmetrical switch costs, any experiment that does mix operations will result in data that overestimate the difficulty of many problems. When basic arithmetic processes are being examined, mixed-operation blocks should be avoided. On the other hand, because operation switching reflects real-life arithmetic situations more accurately, future research should explicitly control operation sequences.

The potential effects of procedural strategy use pose a more challenging problem. Participants spontaneously use a variety of strategies during arithmetic problems. If the difficult levels of strategies used on adjacent trials influence switch costs, then performance on a preceding trial will bias performance on a target trial. Because most experiments do not collect strategy data, it is difficult to know if differential strategy use across problems produces any systematic and confounding effects. 
Finally, Desmet et al. (in press) note that, although researchers remove incorrect trials from response time analyses, they should also remove post-error trials due to their systematic effect on performance. The current work extends this caution from arithmetic verification to arithmetic production, demonstrating similarly systematic effects when participants produce the solution verbally.

In all three of these cases, experiments might be contaminated with systematic effects that are not the focus of the experiment or of interest to the researchers. As such they should be controlled cautiously.

\section{Conclusions}

Participants solve arithmetic problems more slowly when they are required to switch between addition and multiplication on adjacent trials. However, this switch cost is asymmetrical, where addition problems show large switch costs following a difficult multiplication problem whereas multiplication problems are essentially unaffected by the difficult of the preceding problem. In the current work, the asymmetry is argued to be the result of a combination of three sources: Interference between networks, differential use of procedural strategies, and post-error slowing. All three sources may have contributed to high switch costs on addition problems that followed large multiplication problems. Further, the participants in the present study had relatively weak mental arithmetic skills, and thus have weak task sets for solving arithmetic problems, which is potentially a cause of the larger switch costs observed relative to work done in the past. The results of the current study provide further insights into models of the interdependencies between arithmetical operations, as well as provide cautions for future research in mental arithmetic. Experiments that examine 
arithmetic operations in isolation, while fruitful in producing models of mental arithmetic, clearly do not capture the entire picture. 


\section{References}

Anderson, M. C. (2003). Rethinking interference theory: Executive control and the mechanisms of forgetting. Journal of Memory and Language, 49, 415-455. doi:10.1016/j.jml.2003.08.006

Anderson, M. C. (2005). The role of inhibitory control in forgetting unwanted memories: A consideration of three methods. In N. Ohta, C. M. MacLeod, \& B. Uttl (Eds.), Dynamic cognitive processes (pp. 159-189). New York, NY: Springer. doi:10.3758/BF0314366

Allport, D. A., Styles, E. A., \& Hsieh, S. (1994). Shifting intentional set: Exploring the dynamic control of tasks. In C. Umiltà, \& M. Moscovitch (Eds.), (pp. 421-452). Cambridge, MA, US: The MIT Press, Cambridge, MA.

Allport, D. A., \& Wylie, G. (1999). Task-switching: Positive and negative priming of task-set. In G. W. Humphreys, J. Duncan \& A. Treisman (Eds.), (pp. 273-296). New York, NY, US: Oxford University Press, New York, NY.

Arbuthnott, K. D. (2008). Asymmetric switch cost and backward inhibition: Carryover activation and inhibition in switching between tasks of unequal difficulty. Canadian Journal of Experimental Psychology/Revue Canadienne De Psychologie Expérimentale, 62(2), 91-100. doi:10.1037/1196-1961.62.2.91

Arbuthnott, K. D., \& Campbell, J. I. D. (1996). Effects of operand order and problem repetition on error priming in cognitive arithmetic. Canadian Journal of Experimental Psychology/Revue Canadienne De Psychologie Expérimentale, 50(2), 182-196. doi:10.1037/1196-1961.50.2.182 
Arbuthnott, K. D., \& Campbell, J. I. D. (2003). The locus of self-inhibition in sequential retrieval. European Journal of Cognitive Psychology, 15(2), 177-194. doi: $10.1080 / 09541440244000067$

Arbuthnott, K., \& Campbell, J. I. D. (2000). Cognitive inhibition in selection and sequential retrieval. Memory \& Cognition (Pre-2011), 28(3), 331-40.

Arrington, C. M., Logan, G. D., \& Schneider, D. W. (2007). Separating cue encoding from target processing in the explicit task-cuing procedure: Are there "true" task switch effects? Journal of Experimental Psychology: Learning, Memory, and Cognition, 33(3), 484-502.

Ashcraft, M. H., \& Christy, K. S., (1995). The frequency of arithmetic facts in elementary texts: Addition and multiplication in Grades $1-6$. Journal for Research in Mathematics Education, 26(5), 396-421.

Ashcraft, M. H., \& Guillaume, M. M. (2009). Mathematical cognition and the problem size effect. In B. H. Ross (Ed.), The Psychology of Learning and Motivation, 121154. Burlington: Academic Press/Elsevier.

Baddeley, A., Chincotta, D., \& Adlam, A. (2001). Working memory and the control of action: Evidence from task switching. Journal of Experimental Psychology:

General, 130(4), 641-657. doi:10.1037/0096-3445.130.4.641

Bajic, D., Kwak, J., \& Rickard, T. C. (2011). Specificity of learning through memory retrieval practice: The case of addition and subtraction. Psychonomic Bulletin \& Review, 18(6), 1148-1155. doi:10.3758/s13423-011-0151-4 
Botvinick, M. M., Braver, T. S., Barch, D. M., Carter, C. S., \& Cohen, J. D. (2001). Conflict monitoring and cognitive control. Psychological Review, 108(3), 624652. doi:10.1037/0033-295X.108.3.624

Brewer, N., \& Smith, G. A. (1984). How normal and retarded individuals monitor and regulate speed and accuracy of responding in serial choice tasks. Journal of Experimental Psychology: General, 113(1), 71-93. doi:10.1037/00963445.113 .1 .71

Brewer, N., \& Smith, G. A. (1989). Developmental changes in processing speed: Influence of speed-accuracy regulation. Journal of Experimental Psychology: General, 118(3), 298-310. doi:10.1037/0096-3445.118.3.298

Butterworth, B., Zorzi, M., Girelli, L., \& Jonckheere, A. R. (2001). Storage and retrieval of addition facts: The role of number comparison. The Quarterly Journal of Experimental Psychology A: Human Experimental Psychology, 54A(4), 10051029. doi:10.1080/02724980143000064

Campbell, J. I. D. (1987). Production, verification, and priming of multiplication facts. Memory \& Cognition, 15(4), 349-364.

Campbell, J. I. D. (1994). Architectures for numerical cognition. Cognition, 53(1), 144.

Campbell, J. I. D. (1995). Mechanisms of simple addition and multiplication: A modified network-interference theory and simulation. Mathematical Cognition, $1,121-164$. 
Campbell, J. I. D., \& Agnew, H. (2009). Retrieval savings with nonidentical elements: The case of simple addition and subtraction. Psychonomic Bulletin \& Review, 16(5), 938-944. doi:10.3758/PBR.16.5.938

Campbell, J. I. D., \& Alberts, N. M. (2010). Inverse reference in adults-elementary arithmetic. Canadian Journal of Experimental Psychology, 64(2), 77-85.

Campbell, J. I. D., \& Arbuthnott, K. D. (2010). Effects of mixing and cueing simple addition and multiplication. European Journal of Cognitive Psychology, 22(3), 422-442. doi:10.1080/09541440902903629

Campbell, J. I. D., Fuchs-Lacelle, S., \& Phenix, T. L. (2006). Identical elements model of arithmetic memory: Extension to addition and subtraction. Memory \& Cognition (Pre-2011), 34(3), 633-47.

Campbell, J. I. D., \& Graham, D. J. (1985). Mental multiplication skill: Structure, process, and acquisition. Canadian Journal of Psychology/Revue Canadienne De Psychologie, 39(2), 338-366. doi:10.1037/h0080065

Campbell, J. I. D., \& Oliphant, M. (1992). Representation and retrieval of arithmetic facts: A network-interference model and simulation. In J. I. D. Campbell (Ed.), (pp. 331-364). Oxford, England: North-Holland, Oxford. doi:10.1016/S0166$4115(08) 60891-2$

Campbell, J. I. D., \& Phenix, T. L. (2009). Target strength and retrieval-induced forgetting in semantic recall. Memory \& Cognition, 37(1), 65-72. doi:10.3758/MC.37.1.65 
Campbell, J. I. D., \& Robert, N. D. (2008). Bidirectional associations in multiplication memory: Conditions of negative and positive transfer. Journal of Experimental Psychology: Learning, Memory, and Cognition, 34(3), 546-555.

Campbell, J. I. D., \& Thompson, V. A. (2012). Retrieval-induced forgetting of arithmetic facts. Journal of Experimental Psychology: Learning, Memory, and Cognition, 38(1), 118-129. doi:10.1037/a0025056

Campbell, J. I. D., \& Xue, Q. (2001). Cognitive arithmetic across cultures. Journal of Experimental Psychology: General, 130(2), 299-315. doi:10.1037/00963445.130.2.299

Censabella, S., \& Noël, M. (2005). Effects of multiplications on additions in children. Psychology Science, 47(1), 184-196.

Danielmeier, C., Eichele, T., Forstmann, B. U., Tittgemeyer, M., \& Ullsperger, M. (2011). Posterior Medial Frontal Cortex Activity Predicts Post-Error Adaptations in Task-Related Visual and Motor Areas. Journal of Neuroscience, 31(5), 17801789.

De Brauwer, J., \& Fias, W. (2011). The representation of multiplication and division facts in memory: Evidence for cross-operation transfer without mediation. Experimental Psychology, 58(4), 312-323. doi:10.1027/16183169/a000098

Desmet, C., Imbo, I., De Brauwer, J., Brass, M., Fias, W., \& Notebaert, W. (in press). Error adaptation in mental arithmetic. Canadian Journal of Experimental Psychology. 
Fiehler, K., Ullsperger, M., \& Von Cramon, D. (2005). Electrophysiological correlates of error correction. Psychophysiology, 42(1), 72-82. doi:10.1111/j.14698986.2005.00265.x

García-Orza, J., Damas-López, J., Matas, A., \& Rodríguez, J. M. (2009). "2 × 3" primes naming "6": Evidence from masked priming. Attention, Perception, \& Psychophysics, 7I(3), 471-480. doi:10.3758/APP.71.3.471

Geary, D. C. (2000). From infancy to adulthood: The development of numerical abilities. European Child \& Adolescent Psychiatry, 9(Suppl 2), S11-S16. doi: $10.1007 / \mathrm{s} 007870070004$

Gilbert, S. J., \& Shallice, T. (2002). Task switching: A PDP model. Cognitive Psychology, 44(3), 297-337.

Hajcak, G., \& Simons, R. F. (2008). Oops!.. I did it again: An ERP and behavioral study of double-errors. Brain and Cognition, 68(1), 15-21.

doi:10.1016/j.bandc.2008.02.118

Hecht, S. A. (2002). Counting on working memory in simple arithmetic when counting is used for problem solving. Memory \& Cognition, 30(3), 447-455.

Holmes, V. M., \& McGregor, J. (2007). Rote memory and arithmetic fact processing. Memory \& Cognition, 35(8), 2041-2051.

Imbo, I., \& Vandierendonck, A. (2007). The development of strategy use in elementary school children: Working memory and individual differences. Journal of Experimental Child Psychology, 96(4), 284-309.

Imbo, I., \& Vandierendonck, A. (2008). Effects of problem size, operation, and working-memory span on simple-arithmetic strategies: Differences between 
children and adults? Psychological Research, 72(3), 331-346.

doi: $10.1007 / \mathrm{s} 00426-007-0112-8$

Jackson, N., \& Coney, J. (2005). Simple arithmetic processing: The question of automaticity. Acta Psychologica, 119(1), 41-66. doi:10.1016/j.actpsy.2004.10.018

Jackson, N., \& Coney, J. (2007). Simple arithmetic processing: Individual differences in automaticity. European Journal of Cognitive Psychology, 19(1), 141-160. doi:10.1080/09541440600612712

Jersild, A. T. (1927). Mental set and shift. Archives of Psychology, Whole No. 89.

Kiesel, A., Steinhauser, M., Wendt, M., Falkenstein, M., Jost, K., Philipp, A. M., \& Koch, I. (2010). Control and interference in task switching-A review. Psychological Bulletin, 136(5), 849-874. doi:10.1037/a0019842

King, J. A., Korb, F. M., von Cramon, D., \& Ullsperger, M. (2010). Post-error behavioral adjustments are facilitated by activation and suppression of taskrelevant and task-irrelevant information processing. Journal of Neuroscience, 30(38), 12759-12769.

Laming, D. R. (1968). Information theory of choice-reaction times. London: Academic Press.

LeFevre, J., Bisanz, J., Daley, K. E., Buffone, L., Greenham, S. L., \& Sadesky, G. S. (1996). Multiple routes to solution of single-digit multiplication problems. Journal of Experimental Psychology: General, 125(3), 284-306. doi:10.1037/0096-3445.125.3.284 
LeFevre, J., \& Morris, J. (1999). More on the relation between division and multiplication in simple arithmetic: Evidence for mediation of division solutions via multiplication. Memory \& Cognition (Pre-2011), 27(5), 803-12.

LeFevre, J., Sadesky, G. S., \& Bisanz, J. (1996). Selection of procedures in mental addition: Reassessing the problem size effect in adults. Journal of Experimental Psychology: Learning, Memory, and Cognition, 22(1), 216-230. doi:10.1037/0278-7393.22.1.216

Lemaire, P., \& Lecacheur, M. (2010). Strategy switch costs in arithmetic problem solving. Memory \& Cognition, 38(3), 322-332. doi:10.3758/MC.38.3.322

Lemaire, P., \& Siegler, R. S. (1995). Four aspects of strategic change: Contributions to children's learning of multiplication. Journal of Experimental Psychology: General, 124(1), 83-97. doi:10.1037/0096-3445.124.1.83

Logan, G. D. (2003). Executive control of thought and action: In search of the wild homunculus. Current Directions in Psychological Science, 12(2), 45-48. doi:10.1111/1467-8721.01223

Logan, G. D., Schneider, D. W., \& Bundesen, C. (2007). Still clever after all these years: Searching for the homunculus in explicitly cued task switching. Journal of Experimental Psychology: Human Perception and Performance, 33(4), 978-994.

MacLeod, C. M. (1992). The stroop task: The "gold standard" of attentional measures. Journal of Experimental Psychology: General, 121(1), 12-14. doi:10.1037/0096-3445.121.1.12

Mauro, D. G., LeFevre, J., \& Morris, J. (2003). Effects of problem format on division and manipulation performance: Division facts are mediated via multiplication- 
based representations. Journal of Experimental Psychology: Learning, Memory, and Cognition, 29(2), 163-170. doi:10.1037/0278-7393.29.2.163

Mayr, U., \& Kliegl, R. (2000). Task-set switching and long-term memory retrieval. Journal of Experimental Psychology: Learning, Memory, and Cognition, 26(5), 1124-1140. doi:10.1037/0278-7393.26.5.1124

Mayr, U., \& Kliegl, R. (2003). Differential effects of cue changes and task changes on task-set selection costs. Journal of Experimental Psychology: Learning, Memory, and Cognition, 29(3), 362-372. doi:10.1037/0278-7393.29.3.362

Meiran, N. (1996). Reconfiguration of processing mode prior to task performance. Journal of Experiment Psychology: Learning, Memory, and Cognition, 22, 234349.

Metcalfe, A. W., \& Campbell, J. I. (2011). Adults' strategies for simple addition and multiplication: Verbal self-reports and the operand recognition paradigm. Journal of Experimental Psychology: Learning, Memory, and Cognition, 37(3), 661-672. doi: $10.1037 / \mathrm{a} 0022218$

Miller, K. F., \& Paredes, D. R. (1990). Starting to add worse: Effects of learning to multiply on children's addition. Cognition, 37(3), 213-242. doi:10.1016/00100277(90)90046-M

Monsell, S. (2003). Task switching. Trends in Cognitive Sciences, 7(3), 134-140. doi:10.1016/S1364-6613(03)00028-7

Monsell, S., \& Mizon, G. A. (2006). Can the task-cuing paradigm measure an endogenous task-set reconfiguration process? Journal of Experimental Psychology: Human Perception and Performance, 32(3), 493-516. 
Mulhern, G., \& Wylie, J. (2004). Changing levels of numeracy and other core mathematical skills among psychology undergraduates between 1992 and 2002. British Journal of Psychology, 95(3), 355-370.

doi:10.1348/0007126041528176

Notebaert, W., Houtman, F., Opstal, F. V., Gevers, W., Fias, W., \& Verguts, T. (2009). Post-error slowing: An orienting account. Cognition, 111(2), 275-279. doi:10.1016/j.cognition.2009.02.002

Nunes, T., Bryant, P., Hallett, D., Bell, D., \& Evans, D. (2009). Teaching children about the inverse relation between addition and subtraction. Mathematical Thinking and Learning: An International Journal, 11(1-2), 61-78.

Phenix, T. L., \& Campbell, J. I. D. (2004). Effects of multiplication practice on product verification: Integrated structures model of retrieval-induced forgetting? Memory and Cognition, 32, 324-335. doi:10.3758/BF03196862

Rabbitt, P. (1979). How old and young subjects monitor and control responses for accuracy and speed. British Journal of Psychology, 70, 305-311.

Rabbitt, P., \& Rodgers, B. (1977). What does a man do after he makes an error? an analysis of response programming. The Quarterly Journal of Experimental Psychology, 29(4), 727-743. doi:10.1080/14640747708400645

Rickard, T. C. (2005). A revised identical elements model of arithmetic fact representation. Journal of Experimental Psychology: Learning, Memory, and Cognition, 31(2), 250-257. doi:10.1037/0278-7393.31.2.250

Rickard, T. C., Healy, A. F., \& Bourne, L. E. (1994). On the cognitive structure of basic arithmetic skills: Operation, order, and symbol transfer effects. Journal of 
Experimental Psychology: Learning, Memory, and Cognition, 20(5), 1139-1153. doi:10.1037/0278-7393.20.5.1139

Rogers, R. D., \& Monsell, S. (1995). Costs of a predictible switch between simple cognitive tasks. Journal of Experimental Psychology: General, 124(2), 207-231. doi:10.1037/0096-3445.124.2.207

Roussel, J., Fayol, M., \& Barrouillet, P. (2002). Procedural vs. direct retrieval strategies in arithmetic: A comparison between additive and multiplicative problem solving. European Journal of Cognitive Psychology, 14(1), 61-104. doi: $10.1080 / 09541440042000115$

Rubinstein, J. S., Meyer, D. E., \& Evans, J. E. (2001). Executive control of cognitive processes in task switching. Journal of Experimental Psychology: Human Perception and Performance, 27(4), 763-797. doi:10.1037/0096-1523.27.4.763

Schneider, D. W. D., \& Anderson, J. R. J. (2010). Asymmetric switch costs as sequential difficulty effects. Quarterly Journal of Experimental Psychology (2006), 63(10), 1873-1894.

Schneider, D. W., \& Logan, G. D. (2006). Priming cue encoding by manipulating transition frequency in explicitly cued task switching. Psychonomic Bulletin \& Review, 13(1), 145-151.

Schneider, D. W., \& Logan, G. D. (2005). Modeling task switching without switching tasks: A short-term priming account of explicitly cued performance. Journal of Experimental Psychology: General, 134(3), 343-367. 
Schneider, D. W., \& Logan, G. D. (2006). Hierarchical control of cognitive processes: Switching tasks in sequences. Journal of Experimental Psychology: General, 135(4), 623-640.

Schneider, D. W., \& Logan, G. D. (2009). Selecting a response in task switching: Testing a model of compound cue retrieval. Journal of Experimental Psychology: Learning, Memory, and Cognition, 35(1), 122-136.

Schneider, D. W., \& Logan, G. D. (2011). Task-switching performance with 1:1 and 2:1 cue-task mappings: Not so different after all. Journal of Experimental Psychology: Learning, Memory, and Cognition, 37(2), 405-415.

Schneider, M., \& Stern, E. (2009). The inverse relation of addition and subtraction: A knowledge integration perspective. Mathematical Thinking and Learning, 11(12), 92-101. doi:10.1080/10986060802584012

Segalowitz, N., \& Frenkiel-Fishman, S. (2005). Attention control and ability level in a complex cognitive skill: Attention shifting and second-language proficiency. Memory \& Cognition, 33(4), 644-653.

Siegler, R. S. (1988). Strategy choice procedures and the development of multiplication skill. Journal of Experimental Psychology: General, 117, 258-275.

Siegler, R. S. (1989). Strategy diversity and cognitive assessment. Educational Researcher, 18, 15-20.

Siegler, R. S., \& Shrager, J. (1984). Strategy choices in addition and subtraction: How do children know what to do? In C. Sophian (Ed.), The origins of cognitive skills (pp. 229-293). Hillsdale, NJ: Erlbaum. 
Shrager, J., \& Siegler, R. S. (1998). SCADS: A model of children's strategy choices and strategy discoveries. Psychological Science, 9, 405-410.

Smith-Chant, B. L., \& LeFevre, J. (2003). Doing as they are told and telling it like it is: Self-reports in mental arithmetic. Memory \& Cognition (Pre-2011), 31(4), $516-28$.

Spector, A., \& Beiderman, I. (1976). Mental set and mental shift revisited. American Journal of Psychology, 89, 669-679.

Stroop, J. R. (1935). Studies of interference in serial verbal reactions. Journal of Experimental Psychology, 18(6), 643-662. doi:10.1037/h0054651

Thevenot, C., Fanget, M., \& Fayol, M. (2007). Retrieval or nonretrieval strategies in mental arithmetic? an operand recognition paradigm. Memory \& Cognition, 35(6), 1344-1352.

Verguts, T., \& Fias, W. (2005). Interacting neighbors: A connectionist model of retrieval in single-digit multiplication. Memory \& Cognition, 33(1), 1-16.

Verguts, T., \& Fias, W. (2005). Neighbourhood effects in mental arithmetic. Psychology Science, 47(1), 132-140.

Wylie, G. G., \& Allport, A. A. (2000). Task switching and the measurement of "switch costs". Psychological Research, 63(3-4), 212-233.

Yeung, N., \& Monsell, S. (2003). Switching between tasks of unequal familiarity: The role of stimulus-attribute and response-set selection. Journal of Experimental Psychology: Human Perception and Performance,29(2), 455-469. doi:10.1037/0096-1523.29.2.455 
Zbrodoff, N. J., \& Logan, G. D. (1986). On the autonomy of mental processes: A case study of arithmetic. Journal of Experimental Psychology: General, 115(2), 118130. doi:10.1037/0096-3445.115.2.118

Zbrodoff, N. J., \& Logan, G. D. (2005). In Campbell J. I. D. (Ed.), What everyone finds: The problem-size effect. New York, NY, US: Psychology Press, New York, NY.

Zhou, X. (2011). Operation-specific encoding in single-digit arithmetic. Brain and Cognition, 76(3), 400-406 


\section{Appendix A}

The full set of problem sequences presented to participants.

\begin{tabular}{|c|c|c|c|}
\hline Trials $1-2$ & Trials $3-4$ & Trials 5 - 6 & Trials 7 - 8 \\
\hline Small Addition & Small & Large Addition & $\begin{array}{c}\text { Large } \\
\text {. }\end{array}$ \\
\hline & Large & & Small \\
\hline small Adaition & Multiplication & Large Aaumion & Multiplication \\
\hline Large Addition & $\begin{array}{c}\text { Small } \\
\text { Multinlication }\end{array}$ & Small Addition & Large \\
\hline Large Addition & $\begin{array}{l}\text { Large } \\
\text { Multiplication }\end{array}$ & Small Addition & $\begin{array}{l}\text { Small } \\
\text { Multiplication }\end{array}$ \\
\hline Small Multiplication & Small Addition & $\begin{array}{c}\text { Large } \\
\text { Multiplication }\end{array}$ & Large Addition \\
\hline Small Multiplication & Large Addition & $\begin{array}{c}\text { Large } \\
\text { Multiplication }\end{array}$ & Small Addition \\
\hline Large Multiplication & Small Addition & $\begin{array}{c}\text { Small } \\
\text { Multiplication }\end{array}$ & Large Addition \\
\hline Large Multiplication & Large Addition & $\begin{array}{c}\text { Small } \\
\text { Multiplication }\end{array}$ & Small Addition \\
\hline
\end{tabular}

